\title{
Mild Intramolecular Ring Opening of Oxetanes
}

Lindsey G. DeRatt, Edward C. Lawson, Chao-Yuan Wang, Scott D. Kuduk

Janssen R\&D, 1400 McKean Road, Spring House, PA 19477, United States

Table of Contents

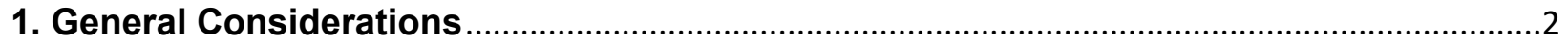

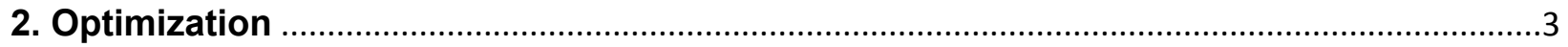

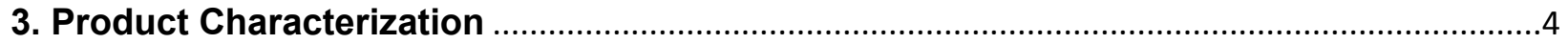

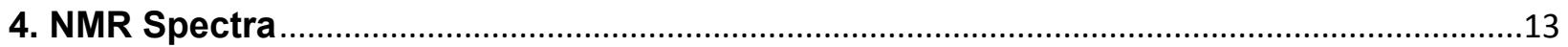




\section{General Considerations}

DriSolv solvents were purchased from EMD Millipore corporation. Analytical thin layer chromatography (TLC) was performed using $250 \mu \mathrm{m}$ Silica Gel 60 F254 pre-coated plates. Flash column chromatography was performed using an Isco with RediSep silica columns. Proton nuclear magnetic resonance (1H NMR) spectra were recorded using a Bruker AVANCE III HD NanoBay 400 NMR spectrometer. Chemical shifts $(\delta)$ are reported in parts per million $(\mathrm{ppm})$ downfield relative to tetramethylsilane (TMS, $0.0 \mathrm{ppm}), \mathrm{CDCl} 3(7.26 \mathrm{ppm})$, MeOD $(3.31 \mathrm{ppm})$, or $\left(\mathrm{CD}_{3}\right)_{2} \mathrm{SO}(2.50 \mathrm{ppm})$. Coupling constants $(\mathrm{J})$ are reported in $\mathrm{Hz}$. Multiplicities are reported using the following abbreviations: $\mathrm{s}$, singlet; d, doublet; $\mathrm{t}$, triplet; $\mathrm{q}$, quartet; $\mathrm{p}$, pentet; $\mathrm{m}$, multiplet; $\mathrm{b}$, broad; Carbon-13 nuclear magnetic resonance (13C NMR) spectra were recorded using a Bruker AVANCE III HD NanoBay 400 NMR spectrometer at $101 \mathrm{MHz}$. Chemical shifts are reported in ppm relative to the carbon resonance of $\mathrm{CDCl} 3$ (77.23 ppm), MeOD (49.01 ppm), or $\left(\mathrm{CD}_{3}\right)_{2} \mathrm{SO}(39.58 \mathrm{ppm})$. High resolution mass spectra (HRMS) are reported as $\mathrm{m} / \mathrm{z}$ (relative ratio). The Instrument Agilent 1260 Infinity Series was used for ESI-TOF analysis (Agilent model 6230). Accurate $\mathrm{m} / \mathrm{z}$ are reported for the molecular ion $[\mathrm{M}+\mathrm{H}]+$. All carboxylic acid and oxetanylamine reagents were purchased from commercial vendors and used without further purification. When heating is indicated in procedure, the reaction was performed using a IKA hot plate with an aluminum block and a thermocouple. 


\section{Optimization}

General procedure for cyclization under basic conditions: To a solution of 14 in DMF (0.3 M) was added base ( 2.0 equiv.) The mixture was heated at the noted temperature for $1-16 \mathrm{~h}$. The $\%$ conversion to $\mathbf{1 5}$ was determined by crude NMR.

\begin{tabular}{|c|c|c|c|}
\hline entry & $\left({ }^{\circ} \mathrm{C}\right)$ & base $(2.0$ equiv. $)$ & conversion to $\mathbf{1 5}(\%)$ \\
\hline 1 & 70 & $\mathrm{Cs}_{2} \mathrm{CO}_{3}$ & $>99$ \\
\hline 2 & 70 & $\mathrm{~K}_{2} \mathrm{CO}_{3}$ & $>99$ \\
\hline 3 & 70 & $\mathrm{DBU}$ & $>99$ \\
\hline 4 & 70 & $\mathrm{Et}_{3} \mathrm{~N}$ & $<10$ \\
\hline 5 & 70 & Pyridine & $<10$ \\
\hline 6 & 50 & $\mathrm{DBU}$ & $>99$ \\
\hline
\end{tabular}

Procedure for cyclization under acidic conditions: To a solution of 14 in THF at $0{ }^{\circ} \mathrm{C}$ was added $\mathrm{BF}_{3} \cdot \mathrm{OEt}_{2}$ (1.0 equiv.). The reaction was complete upon addition to form $\mathbf{4 4}$ and trace $\mathbf{1 5}$ was observed by crude NMR.

\section{General conditions for optimization of one-pot reaction:}

For HATU: To a solution of indazole-3-carboxylic acid (1.0 equiv.) and HATU (1.2 equiv.) in solvent ( 0.3 $\mathrm{M}$ ) was added $\mathrm{N}$-methyloxetan-3-amine (1.2 equiv) followed by $\mathrm{Et}_{3} \mathrm{~N}$ (2.5 equiv.) The mixture was stirred overnight then DBU ( 3.0 equiv.) was added. The mixture was heated at $70^{\circ} \mathrm{C}$ then concentrated in vacuo and purified by column chromatography $(0-10 \% \mathrm{MeOH} / \mathrm{DCM})$.

For CDI: A solution of indazole-3-carboxylic acid (1.0 equiv.) and CDI (1.2 equiv.) in DMF ( $0.3 \mathrm{M})$ was stirred for $1 \mathrm{~h}$ at $70{ }^{\circ} \mathrm{C}$ then $\mathrm{N}$-methyloxetan-3-amine (1.2 equiv) was added. The mixture was stirred overnight then DBU (3.0 equiv.) was added. The mixture was heated at $70{ }^{\circ} \mathrm{C}$ then concentrated in vacuo and purified by column chromatography $(0-10 \% \mathrm{MeOH} / \mathrm{DCM})$.

\begin{tabular}{|c|c|c|c|}
\hline entry & coupling agent & solvent & isolated yield (\%) \\
\hline 1 & HATU & DCE & $<5$ \\
\hline 2 & HATU & 1,4-dioxane & 97 \\
\hline 3 & HATU & MeCN & 71 \\
\hline 4 & HATU & DMF & 97 \\
\hline 5 & CDI & DMF & 78 \\
\hline
\end{tabular}




\section{Product Characterization}<smiles>CC(=O)c1n[nH]c2ccccc12</smiles>

N-methyl-N-(oxetan-3-yl)-1H-indazole-3-carboxamide. To a solution of $1 \mathrm{H}$-indazole-3carboxylic acid $(338 \mathrm{mg}, 2.1 \mathrm{mmol})$ and HATU $(951 \mathrm{mg}, 2.5 \mathrm{mmol})$ in DMF $(3.0 \mathrm{~mL})$ was added $\mathrm{Et}_{3} \mathrm{~N}$ $(0.58 \mathrm{~mL}, 0.728 \mathrm{~g} / \mathrm{mL}, 4.17 \mathrm{mmol})$ followed by $\mathrm{N}$-methyloxetan-3-amine $(0.22 \mathrm{~mL}, 0.979 \mathrm{~g} / \mathrm{mL}, 2.50$ $\mathrm{mmol}$ ). The mixture was stirred at room temperature for $24 \mathrm{~h}$ then diluted with EtOAc and water. The organics were extracted with EtOAc, washed with brine, and dried over sodium sulfate. Purification by column chromatography (70-80\% EtOAc/heptane) afforded the title compound as a white solid (454 $\mathrm{mg}, 94 \%$ yield). ${ }^{1 \mathrm{H}} \mathrm{NMR}\left(400 \mathrm{MHz}\right.$, Methanol- $\left.d_{4}\right) \delta 7.95$ (br s, $\left.1 \mathrm{H}\right), 7.58(\mathrm{~d}, J=8.4 \mathrm{~Hz}, 1 \mathrm{H}), 7.43(\mathrm{t}, \mathrm{J}$ $=7.7 \mathrm{~Hz}, 1 \mathrm{H}), 7.24(\mathrm{t}, J=7.6 \mathrm{~Hz}, 1 \mathrm{H}), 5.97-5.30(\mathrm{~m}, 1 \mathrm{H}), 4.89-4.80(\mathrm{~m}, 4 \mathrm{H}), 3.41(\mathrm{~s}, 3 \mathrm{H}) .13 \mathrm{C}$ NMR peaks not assigned due to ambiguous spectra (vide infra). HRMS (ESI) m/z: $[\mathrm{M}+\mathrm{H}]^{+}$calculated for $\mathrm{C}_{12} \mathrm{H}_{13} \mathrm{~N}_{3} \mathrm{O}_{2} \mathrm{H}^{+}$232.1086; found 232.1093.

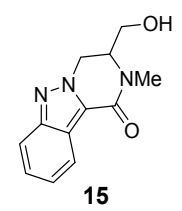

3-(hydroxymethyl)-2-methyl-3,4-dihydropyrazino[1,2-b]indazol-1(2H)-one. To a solution of indazole-3-carboxylic acid $(100 \mathrm{mg}, 0.62 \mathrm{mmol})$ and HATU $(281 \mathrm{mg}, 0.74 \mathrm{mmol})$ in DMF $(2.0 \mathrm{~mL})$ was added $\mathrm{N}$-methyloxetan-3-amine $(66 \mu \mathrm{L}, 0.979 \mathrm{~g} / \mathrm{mL}, 0.74 \mathrm{mmol})$ followed by $\mathrm{Et}_{3} \mathrm{~N}(0.21 \mathrm{~mL}, 0.728$ $\mathrm{g} / \mathrm{mL}, 1.5 \mathrm{mmol})$. The mixture was stirred overnight then DBU $(0.28 \mathrm{~mL}, 1.019 \mathrm{~g} / \mathrm{mL}, 1.9 \mathrm{mmol})$ was added. The mixture was heated at $70^{\circ} \mathrm{C}$ for $5 \mathrm{~h}$. The mixture was concentrated in vacuo then purified by column chromatography $(0-10 \% \mathrm{MeOH} / \mathrm{DCM})$ to afford the title compound as a white solid (139 $\mathrm{mg}, 97 \%$ yield). ${ }^{1} \mathrm{H}$ NMR $\left(400 \mathrm{MHz}\right.$, Methanol- $\left.d_{4}\right) \delta 8.05(\mathrm{~d}, J=8.4 \mathrm{~Hz}, 1 \mathrm{H}), 7.70(\mathrm{~d}, J=8.7 \mathrm{~Hz}, 1 \mathrm{H})$, $7.44-7.32(\mathrm{~m}, 1 \mathrm{H}), 7.30-7.21(\mathrm{~m}, 1 \mathrm{H}), 4.83(\mathrm{~d}, J=3.3 \mathrm{~Hz}, 2 \mathrm{H}), 3.98(\mathrm{~m}, 1 \mathrm{H}), 3.72(\mathrm{dd}, J=11.3$, $4.9 \mathrm{~Hz}, 1 \mathrm{H}), 3.47(\mathrm{dd}, J=11.2,7.9 \mathrm{~Hz}, 1 \mathrm{H}), 3.23(\mathrm{~s}, 3 \mathrm{H}) .{ }^{13} \mathrm{C} \mathrm{NMR}\left(101 \mathrm{MHz}\right.$, Methanol- $\left.d_{4}\right) \delta 158.2$, $148.2,126.5,124.7,124.2,121.1,120.3,117.1,59.5,58.9,47.4,32.2$. HRMS (ESI) m/z: $[M+H]^{+}$ calculated for $\mathrm{C}_{12} \mathrm{H}_{13} \mathrm{~N}_{3} \mathrm{O}_{2} \mathrm{H}^{+} 232.1086$; found 232.1094.

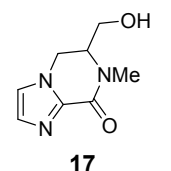

6-(hydroxymethyl)-7-methyl-6,7-dihydroimidazo[1,2-a]pyrazin-8(5H)-one. A mixture of $1 \mathrm{H}$ imidazole-2-carboxylic acid (143 mg, $1.276 \mathrm{mmol})$ and CDI $(248 \mathrm{mg}, 1.53 \mathrm{mmol})$ in DMF was stirred at $70{ }^{\circ} \mathrm{C}$ for $2 \mathrm{~h}$ then $\mathrm{N}$-methyloxetan-3-amine $(136 \mu \mathrm{L}, 0.979 \mathrm{~g} / \mathrm{mL}, 1.53 \mathrm{mmol})$ was added. The mixture was stirred for an additional $2 \mathrm{~h}$ then DBU $(0.572 \mathrm{~mL}, 1.019 \mathrm{~g} / \mathrm{mL}, 3.827 \mathrm{mmol})$ was added to the reaction. The mixture was heated at $70{ }^{\circ} \mathrm{C}$ for $6 \mathrm{~h}$ then concentrated and purified by column chromatography $(0-15 \% \mathrm{MeOH} / \mathrm{DCM})$ to afford the product as a white solid (129 mg, yield $56 \%) .{ }^{1} \mathrm{H}$ NMR $\left(400 \mathrm{MHz}\right.$, Methanol- $\left.d_{4}\right) \delta 7.23(\mathrm{~s}, 1 \mathrm{H}), 7.15(\mathrm{~s}, 1 \mathrm{H}), 4.51-4.39(\mathrm{~m}, 2 \mathrm{H}), 3.88-3.80(\mathrm{~m}, 1 \mathrm{H})$, $3.69(\mathrm{dd}, J=11.3,5.0 \mathrm{~Hz}, 1 \mathrm{H}), 3.43(\mathrm{dd}, J=11.3,8.0 \mathrm{~Hz}, 1 \mathrm{H}), 3.18(\mathrm{~s}, 3 \mathrm{H}) .{ }^{13} \mathrm{C} \mathrm{NMR}(101 \mathrm{MHz}$, DMSO- $\left.d_{6}\right) \delta 156.3,138.1,130.1,121.8,59.5,58.9,43.0,33.6$. HRMS (ESI) m/z: $[\mathrm{M}+\mathrm{H}]^{+}$calculated for $\mathrm{C}_{8} \mathrm{H}_{11} \mathrm{~N}_{3} \mathrm{O}_{2} \mathrm{H}^{+}$182.0930; found 182.0936 .

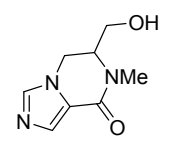

18

6-(hydroxymethyl)-7-methyl-6,7-dihydroimidazo[1,5-a]pyrazin-8(5H)-one. $1 \mathrm{H}$-imidazole-4carboxylic acid (134 mg, $1.2 \mathrm{mmol})$, CDI $(232.6 \mathrm{mg}, 1.4 \mathrm{mmol})$ in DMF was stirred at $70^{\circ} \mathrm{C}$ for $2 \mathrm{~h}$ then $\mathrm{N}$-methyloxetan-3-amine $(128 \mu \mathrm{L}, 0.979 \mathrm{~g} / \mathrm{mL}, 1.4 \mathrm{mmol})$ was added. The mixture was stirred an 
additional $2 \mathrm{~h}$ then DBU $(0.54 \mathrm{~mL}, 1.019 \mathrm{~g} / \mathrm{mL}, 3.6 \mathrm{mmol})$ was added and the mixture heated at $70{ }^{\circ} \mathrm{C}$ for $6 \mathrm{~h}$. The mixture was concentrated then purified by column chromatography $(0-15 \% \mathrm{MeOH} / \mathrm{DCM})$ to afford the product as a white solid $(112 \mathrm{mg}$, yield $52 \%) .{ }^{1} \mathrm{H} \mathrm{NMR}\left(400 \mathrm{MHz}\right.$, Methanol- $\left.d_{4}\right) \delta 7.79(\mathrm{~s}$, $1 \mathrm{H}), 7.55(\mathrm{~s}, 1 \mathrm{H}), 4.57(\mathrm{dd}, J=13.3,1.5 \mathrm{~Hz}, 1 \mathrm{H}), 4.31(\mathrm{dd}, J=13.3,4.8 \mathrm{~Hz}, 1 \mathrm{H}), 3.88-3.77(\mathrm{~m}$, $1 \mathrm{H}), 3.66(\mathrm{dd}, \mathrm{J}=11.2,5.1 \mathrm{~Hz}, 1 \mathrm{H}), 3.39(\mathrm{dd}, J=11.2,8.2 \mathrm{~Hz}, 1 \mathrm{H}), 3.17(\mathrm{~s}, 3 \mathrm{H}) .{ }^{13} \mathrm{C} \mathrm{NMR}(101 \mathrm{MHz}$, DMSO- $\left.d_{6}\right) \delta 157.6,138.5,131.4,124.1,59.2,59.1,41.9,33.2$. HRMS (ESI) m/z: $[\mathrm{M}+\mathrm{H}]^{+}$calculated for $\mathrm{C}_{8} \mathrm{H}_{11} \mathrm{~N}_{3} \mathrm{O}_{2} \mathrm{H}^{+}$182.0930; found 182.0938 .

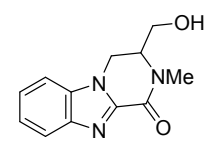

19

3-(hydroxymethyl)-2-methyl-3,4-dihydrobenzo[4,5]imidazo[1,2-a]pyrazin-1(2H)-one. To a solution of $1 \mathrm{H}$-benzimidazole-2-carboxylic acid $(200 \mathrm{mg}, 1.2 \mathrm{mmol})$ and HATU $(562.8 \mathrm{mg}, 1.5 \mathrm{mmol})$ in DMF $(4 \mathrm{~mL})$ was added $\mathrm{N}$-methyloxetan-3-amine $(0.13 \mathrm{~mL}, 0.979 \mathrm{~g} / \mathrm{mL}, 1.5 \mathrm{mmol})$ followed by $\mathrm{Et}_{3} \mathrm{~N}(0.43 \mathrm{~mL}, 0.728 \mathrm{~g} / \mathrm{mL}, 3.1 \mathrm{mmol})$. The mixture was stirred overnight then $\mathrm{DBU}(0.55 \mathrm{~mL}, 1.019$ $\mathrm{g} / \mathrm{mL}, 3.7 \mathrm{mmol}$ ) was added and heated to $70^{\circ} \mathrm{C}$. Upon full conversion to the cyclized product, the mixture was concentrated in vacuo then purified by column chromatography $(0-10 \% \mathrm{MeOH} / \mathrm{DCM})$ to afford the product as a pale yellow solid (208 mg, 73\% yield). ${ }^{1} \mathrm{H}$ NMR (400 MHz, Methanol- $\left.d_{4}\right) \delta 7.77$ $(\mathrm{d}, J=8.1 \mathrm{~Hz}, 1 \mathrm{H}), 7.61(\mathrm{~d}, J=8.3 \mathrm{~Hz}, 1 \mathrm{H}), 7.50-7.42(\mathrm{~m}, 1 \mathrm{H}), 7.40-7.31(\mathrm{~m}, 1 \mathrm{H}), 4.72(\mathrm{dd}, J=$ $13.2,1.4 \mathrm{~Hz}, 1 \mathrm{H}), 4.52(\mathrm{dd}, J=13.1,5.2 \mathrm{~Hz}, 1 \mathrm{H}), 4.11-3.96(\mathrm{~m}, 1 \mathrm{H}), 3.74(\mathrm{dd}, J=11.5,4.6 \mathrm{~Hz}$, $1 \mathrm{H}), 3.54(\mathrm{dd}, J=11.5,7.4 \mathrm{~Hz}, 1 \mathrm{H}), 3.28(\mathrm{~s}, 3 \mathrm{H}) .{ }^{13} \mathrm{C}$ NMR $\left(101 \mathrm{MHz}\right.$, Methanol- $\left.d_{4}\right) \delta 157.0,142.1$, $141.7,133.8,124.9,123.5,120.0,110.5,60.0,59.3,40.7,33.0$. HRMS (ESI) m/z: $[\mathrm{M}+\mathrm{H}]^{+}$ calculated for $\mathrm{C}_{12} \mathrm{H}_{13} \mathrm{~N}_{3} \mathrm{O}_{2} \mathrm{H}^{+} 232.1086$; found 232.1096.

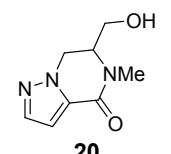

6-(hydroxymethyl)-5-methyl-6,7-dihydropyrazolo[ $1,5-$ a]pyrazin-4(5H)-one. To a solution of $1 \mathrm{H}$-pyrazole-5-carboxylic acid (200 mg, $1.8 \mathrm{mmol})$ and HATU $(814.1 \mathrm{mg}, 2.1 \mathrm{mmol})$ in DMF $(5.8 \mathrm{~mL})$ was added $\mathrm{N}$-methyloxetan-3-amine $(0.19 \mathrm{~mL}, 0.979 \mathrm{~g} / \mathrm{mL}, 2.1 \mathrm{mmol})$ followed by $\mathrm{Et}_{3} \mathrm{~N}(0.62 \mathrm{~mL}$, $0.728 \mathrm{~g} / \mathrm{mL}, 4.5 \mathrm{mmol})$. The mixture was stirred overnight then DBU $(0.8 \mathrm{~mL}, 1.019 \mathrm{~g} / \mathrm{mL}, 5.4 \mathrm{mmol})$ was added and heated to $70^{\circ} \mathrm{C}$ for $5 \mathrm{~h}$. The mixture was concentrated in vacuo then purified by column chromatography (0-10\% $\mathrm{MeOH} / \mathrm{DCM})$ to afford the product as a colorless oil ( $318 \mathrm{mg}, 98 \%$ yield). ${ }^{1} \mathrm{H}$ NMR $\left(400 \mathrm{MHz}\right.$, Methanol- $\left.d_{4}\right) \delta 7.53(\mathrm{~d}, J=2.0 \mathrm{~Hz}, 1 \mathrm{H}), 6.75(\mathrm{~d}, J=2.0 \mathrm{~Hz}, 1 \mathrm{H}), 4.55$ (dd, $J=13.4,1.4 \mathrm{~Hz}, 1 \mathrm{H}), 4.43(\mathrm{dd}, J=13.4,5.1 \mathrm{~Hz}, 1 \mathrm{H}), 3.90-3.81(\mathrm{~m}, 1 \mathrm{H}), 3.65(\mathrm{dd}, J=11.2,5.1$ $\mathrm{Hz}, 1 \mathrm{H}), 3.40(\mathrm{dd}, J=11.2,8.1 \mathrm{~Hz}, 1 \mathrm{H}), 3.16(\mathrm{~s}, 3 \mathrm{H}) .{ }^{13} \mathrm{C} \mathrm{NMR}\left(101 \mathrm{MHz}\right.$, Methanol- $\left.d_{4}\right) \delta 158.0$, 139.1, 133.4, 106.7, 59.4, 59.3, 45.7, 32.6. HRMS (ESI) $\mathrm{m} / \mathrm{z}:[\mathrm{M}+\mathrm{H}]^{+}$calculated for $\mathrm{C}_{8} \mathrm{H}_{11} \mathrm{~N}_{3} \mathrm{O}_{2} \mathrm{H}^{+}$ 182.0930; found 182.0925 .

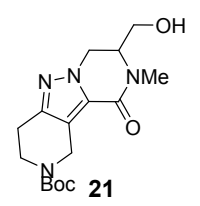

tert-butyl 8-(hydroxymethyl)-9-methyl-10-oxo-3,4,7,8,9,10hexahydropyrido [4',3':3,4]pyrazolo [1,5-a]pyrazine-2(1H)-carboxylate. To a solution of 5(tert-butoxycarbonyl)-4,5,6,7-tetrahydro-2H-pyrazolo[4,3-c]pyridine-3-carboxylic acid ${ }^{1}$ (200 mg, 0.75 $\mathrm{mmol})$ and HATU $(341.4 \mathrm{mg}, 0.90 \mathrm{mmol})$ in DMF $(2.4 \mathrm{~mL})$ was added $\mathrm{N}$-methyloxetan-3-amine (80 $\mu \mathrm{L}, 0.979 \mathrm{~g} / \mathrm{mL}, 0.90 \mathrm{mmol})$ followed by $\mathrm{Et}_{3} \mathrm{~N}(0.26 \mathrm{~mL}, 0.728 \mathrm{~g} / \mathrm{mL}, 1.9 \mathrm{mmol})$. The mixture was stirred overnight then DBU $(0.8 \mathrm{~mL}, 1.019 \mathrm{~g} / \mathrm{mL}, 5.4 \mathrm{mmol})$ was added and heated to $70^{\circ} \mathrm{C}$. Upon full conversion to the cyclized product, the mixture was concentrated in vacuo then purified by column chromatography $(0-10 \% \mathrm{MeOH} / \mathrm{DCM})$ to afford the product as a pale yellow solid $(236 \mathrm{mg}, 94 \%$ yield). ${ }^{1} \mathrm{H}$ NMR $\left(400 \mathrm{MHz}\right.$, Methanol- $\left.d_{4}\right) \delta 4.63(\mathrm{~m}, 2 \mathrm{H}), 4.49(\mathrm{dd}, J=13.4,1.6 \mathrm{~Hz}, 1 \mathrm{H}), 4.39(\mathrm{dd}, J=$ $13.3,5.0 \mathrm{~Hz}, 1 \mathrm{H}), 3.84(\mathrm{~m}, 1 \mathrm{H}), 3.79-3.61(\mathrm{~m}, 3 \mathrm{H}), 3.46(\mathrm{dd}, J=11.2,8.0 \mathrm{~Hz}, 1 \mathrm{H}), 3.16(\mathrm{~s}, 3 \mathrm{H})$, 
$2.72(\mathrm{t}, \mathrm{J}=5.9 \mathrm{~Hz}, 2 \mathrm{H}), 1.48(\mathrm{~s}, 9 \mathrm{H}) .13 \mathrm{C}$ NMR peaks not assigned due to ambiguous spectra. . HRMS (ESI) m/z: [M+H] calculated for $\mathrm{C}_{16} \mathrm{H}_{24} \mathrm{~N}_{4} \mathrm{O}_{4} \mathrm{H}^{+} 337.1876$; found 337.1880.

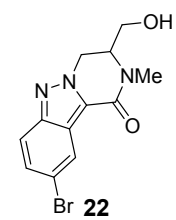

9-bromo-3-(hydroxymethyl)-2-methyl-3,4-dihydropyrazino[1,2-b]indazol-1(2H)-one. To a solution of 5-bromo-1H-indazole-3-carboxylic acid (159 mg, $0.66 \mathrm{mmol}$ ) and HATU (301 mg, $0.79 \mathrm{mmol})$ in DMF $(2.3 \mathrm{~mL})$ was added $\mathrm{Et}_{3} \mathrm{~N}(0.18 \mathrm{~mL}, 0.728 \mathrm{~g} / \mathrm{mL}, 1.3 \mathrm{mmol})$ followed by $\mathrm{N}-$ methyloxetan-3-amine $(70 \mu \mathrm{L}, 0.979 \mathrm{~g} / \mathrm{mL}, 0.79 \mathrm{mmol})$. The mixture was stirred overnight then DBU $(0.30 \mathrm{~mL}, 1.019 \mathrm{~g} / \mathrm{mL}, 2.0 \mathrm{mmol})$ was added and the mixture heated at $70{ }^{\circ} \mathrm{C}$ for $4 \mathrm{~h}$. The mixture was concentrated in vacuo and dissolved in EtOAc. Water was added and the organics were extracted with EtOAc (3x). The combined organic layers were washed with brine, dried over sodium sulfate, filtered and concentrated. Purification by column chromatography ( $0-10 \% \mathrm{MeOH} / \mathrm{DCM})$ afforded the title compound as an off-white solid (166 mg, $81 \%$ yield). ${ }^{1} \mathrm{H}$ NMR (400 MHz, Chloroform- $d$ ) $\delta 8.31$ (d, $J=1.7 \mathrm{~Hz}, 1 \mathrm{H}), 7.61(\mathrm{~d}, J=9.1 \mathrm{~Hz}, 1 \mathrm{H}), 7.42(\mathrm{dd}, \mathrm{J}=9.1,1.7 \mathrm{~Hz}, 1 \mathrm{H}), 4.91(\mathrm{dd}, J=14.0,1.3 \mathrm{~Hz}$, $1 \mathrm{H}), 4.75(\mathrm{dd}, J=14.0,5.0 \mathrm{~Hz}, 1 \mathrm{H}), 3.96-3.80(\mathrm{~m}, 2 \mathrm{H}), 3.65-3.54(\mathrm{~m}, 1 \mathrm{H}), 3.27(\mathrm{~s}, 3 \mathrm{H}), 2.06(\mathrm{t}$, $\mathrm{J}=4.7 \mathrm{~Hz}, 1 \mathrm{H}) .{ }^{13} \mathrm{C} \mathrm{NMR}(101 \mathrm{MHz}$, Chloroform-d) $\delta 157.5,146.9,130.5,124.5,123.1,122.5$, 119.3, 118.6, 60.1, 58.8, 47.9, 33.4. HRMS (ESI) m/z: $[M+H]^{+}$calculated for $\mathrm{C}_{12} \mathrm{H}_{12} \mathrm{BrN}_{3} \mathrm{O}_{2} \mathrm{H}^{+}$ 310.0191 ; found 310.0197 .

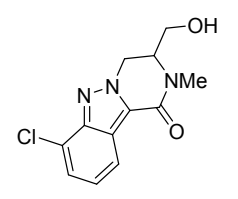

23

7-chloro-3-(hydroxymethyl)-2-methyl-3,4-dihydropyrazino[1,2-b]indazol-1(2H)-one. To a solution of 7-chloro-1H-indazole-3-carboxylic acid (160 mg, $0.8 \mathrm{mmol}$ ) and HATU (371 mg, 0.98 $\mathrm{mmol})$ in DMF $(2.7 \mathrm{~mL})$ was added $\mathrm{Et}_{3} \mathrm{~N}(0.23 \mathrm{~mL}, 0.728 \mathrm{~g} / \mathrm{mL}, 1.63 \mathrm{mmol})$ followed by $\mathrm{N}-$

methyloxetan-3-amine $(87 \mu \mathrm{L}, 0.979 \mathrm{~g} / \mathrm{mL}, 0.98 \mathrm{mmol})$. The mixture was stirred at room temperature overnight then DBU $(0.45 \mathrm{~mL}, 1.019 \mathrm{~g} / \mathrm{mL}, 3.0 \mathrm{mmol})$ was added. The reaction was heated to $70{ }^{\circ} \mathrm{C}$ and stirred $5 \mathrm{~h}$ then concentrated. The crude material was dissolved in water and EtOAc. The organics were extracted with EtOAc (3x), washed with brine, dried over sodium sulfate, filtered and concentrated. Purification by column chromatography (60-80\% EtOAc/heptane) provided the title compound as an off-white solid (163 mg, 76\% yield). ${ }^{1} \mathrm{H}$ NMR (400 MHz, Chloroform-d) $\delta 8.06$ (d, $J=$ $8.4 \mathrm{~Hz}, 1 \mathrm{H}), 7.39(\mathrm{~d}, J=7.3 \mathrm{~Hz}, 1 \mathrm{H}), 7.22-7.16(\mathrm{~m}, 1 \mathrm{H}), 5.01(\mathrm{dd}, J=14.1,1.3 \mathrm{~Hz}, 1 \mathrm{H}), 4.78(\mathrm{dd}$, $J=14.1,5.1 \mathrm{~Hz}, 1 \mathrm{H}), 3.98-3.79(\mathrm{~m}, 2 \mathrm{H}), 3.69-3.54(\mathrm{~m}, 1 \mathrm{H}), 3.28(\mathrm{~s}, 3 \mathrm{H}), 2.03(\mathrm{~s}, 1 \mathrm{H}) .{ }^{13} \mathrm{C} \mathrm{NMR}$ $(101 \mathrm{MHz} \text {, DMSO-d })_{6} \delta 157.2,145.1,126.5,126.0,125.0,122.5,122.3,120.2,59.9,58.5,48.5$, 33.0. HRMS (ESI) m/z: $[\mathrm{M}+\mathrm{H}]^{+}$calculated for $\mathrm{C}_{12} \mathrm{H}_{12} \mathrm{ClN}_{3} \mathrm{O}_{2} \mathrm{H}^{+}$266.0516; found 266.0703.

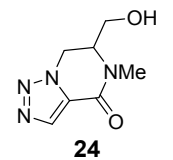

6-(hydroxymethyl)-5-methyl-6,7-dihydro-[1,2,3]triazolo[1,5-a]pyrazin-4(5H)-one. To a mixture of $1 \mathrm{H}-1,2,3$-triazole-4-carboxylic acid (130 mg, $1.2 \mathrm{mmol}$ ) and HATU (525 mg, $1.4 \mathrm{mmol})$ in DMF $(3.7 \mathrm{~mL})$ was added $\mathrm{Et}_{3} \mathrm{~N}(0.4 \mathrm{~mL}, 0.728 \mathrm{~g} / \mathrm{mL}, 2.9 \mathrm{mmol})$ followed by $\mathrm{N}$-methyloxetan-3-amine $(123 \mu \mathrm{L}, 0.979 \mathrm{~g} / \mathrm{mL}, 1.4 \mathrm{mmol})$. The mixture was stirred at room temperature overnight then DBU $(0.52 \mathrm{~mL}, 1.019 \mathrm{~g} / \mathrm{mL}, 3.5 \mathrm{mmol})$ was added and heated at $70{ }^{\circ} \mathrm{C}$ for $5 \mathrm{~h}$. The mixture was then concentrated and purified by column chromatography (0-20\% MeOH/DCM) to afford the title compound as a tan solid (154 mg, 74\% yield). ${ }^{1} \mathrm{H}$ NMR (400 MHz, Methanol- $\left.d_{4}\right) \delta 8.13(\mathrm{~s}, 1 \mathrm{H}), 4.98$ $(\mathrm{dd}, \mathrm{J}=13.8,1.3 \mathrm{~Hz}, 1 \mathrm{H}), 4.72(\mathrm{dd}, \mathrm{J}=13.8,5.5 \mathrm{~Hz}, 1 \mathrm{H}), 4.08-3.97(\mathrm{~m}, 1 \mathrm{H}), 3.70(\mathrm{dd}, J=11.6$, $4.5 \mathrm{~Hz}, 1 \mathrm{H}), 3.52(\mathrm{dd}, J=11.5,6.9 \mathrm{~Hz}, 1 \mathrm{H}), 3.22(\mathrm{~s}, 3 \mathrm{H}) .{ }^{13} \mathrm{C}$ NMR $\left(101 \mathrm{MHz}\right.$, Methanol- $\left.d_{4}\right) \delta 156.6$, 
133.1, 129.3, 59.8, 59.2, 45.1, 32.3. HRMS (ESI) $\mathrm{m} / \mathrm{z}$ : $[\mathrm{M}+\mathrm{H}]^{+}$calculated for $\mathrm{C}_{7} \mathrm{H}_{10} \mathrm{~N}_{4} \mathrm{O}_{2} \mathrm{H}^{+} 183.0882$; found 183.0885 .

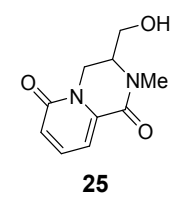

3-(hydroxymethyl)-2-methyl-3,4-dihydro-2H-pyrido[1,2-a]pyrazine-1,6-dione. To a mixture of 6-hydroxypicolinic acid $(161 \mathrm{mg}, 1.2 \mathrm{mmol})$ and HATU $(528 \mathrm{mg}, 1.4 \mathrm{mmol})$ in DMF $(3.9 \mathrm{~mL})$ was added $\mathrm{Et}_{3} \mathrm{~N}(0.32 \mathrm{~mL}, 0.728 \mathrm{~g} / \mathrm{mL}, 2.3 \mathrm{mmol})$ followed by $\mathrm{N}$-methyloxetan-3-amine $(0.12 \mathrm{~mL}, 0.979$ $\mathrm{g} / \mathrm{mL}, 1.4 \mathrm{mmol})$. The mixture was stirred at room temperature overnight then DBU $(0.52 \mathrm{~mL}, 1.019$ $\mathrm{g} / \mathrm{mL}, 3.5 \mathrm{mmol}$ ) was added. The reaction was heated to $70^{\circ} \mathrm{C}$ for $24 \mathrm{~h}$ then concentrated.

Purification by column chromatography (0-5\% MeOH/DCM) afforded the title compound as a yellow solid $\left(185 \mathrm{mg}, 77 \%\right.$ yield). ${ }^{1} \mathrm{H}$ NMR $\left(400 \mathrm{MHz}, \mathrm{DMSO}-d_{6}\right) \delta 7.51$ (dd, $\left.J=9.2,6.9 \mathrm{~Hz}, 1 \mathrm{H}\right), 6.90$ (dd, $J$ $=6.9,1.2 \mathrm{~Hz}, 1 \mathrm{H}), 6.61(\mathrm{dd}, J=9.2,1.2 \mathrm{~Hz}, 1 \mathrm{H}), 5.10(\mathrm{t}, J=5.2 \mathrm{~Hz}, 1 \mathrm{H}), 4.68(\mathrm{dd}, J=13.9,1.2$ $\mathrm{Hz}, 1 \mathrm{H}), 3.80-3.66(\mathrm{~m}, 2 \mathrm{H}), 3.56-3.44(\mathrm{~m}, 1 \mathrm{H}), 3.38-3.25(\mathrm{~m}, 1 \mathrm{H}), 3.07(\mathrm{~s}, 3 \mathrm{H}) .{ }^{13} \mathrm{C}$ NMR $(101$ $\mathrm{MHz}$, Methanol- $\left.d_{4}\right) \delta 161.9,158.4,139.5,137.0,122.7,108.6,60.1,57.1,40.2,33.6$. HRMS (ESI) $\mathrm{m} / \mathrm{z}:[\mathrm{M}+\mathrm{H}]^{+}$calculated for $\mathrm{C}_{10} \mathrm{H}_{12} \mathrm{~N}_{2} \mathrm{O}_{3} \mathrm{H}^{+}$209.0926; found 209.0930.

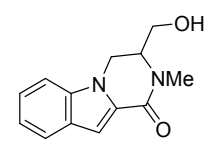

26

3-(hydroxymethyl)-2-methyl-3,4-dihydropyrazino[1,2-a]indol-1(2H)-one. To a mixture of $1 \mathrm{H}$ indole-2-carboxylic acid $(200 \mathrm{mg}, 1.24 \mathrm{mmol})$ and HATU $(566 \mathrm{mg}, 1.49 \mathrm{mmol})$ in DMF $(4.0 \mathrm{~mL})$ was added $\mathrm{Et}_{3} \mathrm{~N}(0.0 .43 \mathrm{~mL}, 0.728 \mathrm{~g} / \mathrm{mL}, 3.1 \mathrm{mmol})$ followed by $\mathrm{N}$-methyloxetan-3-amine $(0.13 \mathrm{~mL}, 0.979$ $\mathrm{g} / \mathrm{mL}, 1.49 \mathrm{mmol})$. The mixture was stirred at room temperature overnight then DBU $(0.56 \mathrm{~mL}, 1.019$ $\mathrm{g} / \mathrm{mL}, 3.72 \mathrm{mmol}$ ) was added. The reaction was heated to $70^{\circ} \mathrm{C}$ for $24 \mathrm{~h}$ then concentrated.

Purification by column chromatography $(0-10 \% \mathrm{MeOH} / \mathrm{DCM})$ afforded the title compound as a white solid $\left(281 \mathrm{mg}, 98 \%\right.$ yield). ${ }^{1} \mathrm{H}$ NMR $\left(400 \mathrm{MHz}\right.$, Methanol- $\left.d_{4}\right) \delta 7.65(\mathrm{~d}, J=8.1 \mathrm{~Hz}, 1 \mathrm{H}), 7.45(\mathrm{~d}, J=$ $8.4 \mathrm{~Hz}, 1 \mathrm{H}), 7.35-7.28(\mathrm{~m}, 1 \mathrm{H}), 7.16-7.08(\mathrm{~m}, 2 \mathrm{H}), 4.71-4.61(\mathrm{~m}, 1 \mathrm{H}), 4.22(\mathrm{dd}, \mathrm{J}=12.7,4.5$ $\mathrm{Hz}, 1 \mathrm{H}), 3.95-3.84(\mathrm{~m}, 1 \mathrm{H}), 3.70(\mathrm{dd}, J=11.0,5.2 \mathrm{~Hz}, 1 \mathrm{H}), 3.43(\mathrm{dd}, J=11.0,8.6 \mathrm{~Hz}, 1 \mathrm{H}), 3.24$ $(\mathrm{s}, 3 \mathrm{H}) .{ }^{13} \mathrm{C}$ NMR $\left(101 \mathrm{MHz}\right.$, Methanol- $\left.d_{4}\right) \delta 160.3,137.1,128.0,127.3,124.3,121.9,120.4,109.6$, 105.0, 60.0, 59.5, 39.8, 33.0. HRMS (ESI) $\mathrm{m} / \mathrm{z}$ : $[\mathrm{M}+\mathrm{H}]+$ calculated for $\mathrm{C}_{13} \mathrm{H}_{14} \mathrm{~N}_{2} \mathrm{O}_{2} \mathrm{H}^{+} 231.1134$; found 231.1142 .

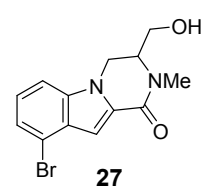

9-bromo-3-(hydroxymethyl)-2-methyl-3,4-dihydropyrazino[1,2-a]indol-1(2H)-one. To a solution of 4-bromo-1H-indole-2-carboxylic acid $(181 \mathrm{mg}, 0.75 \mathrm{mmol})$ and HATU (344 mg, 0.91 $\mathrm{mmol})$ in DMF $(2.5 \mathrm{~mL})$ was added $\mathrm{Et}_{3} \mathrm{~N}(0.21 \mathrm{~mL}, 0.728 \mathrm{~g} / \mathrm{mL}, 1.51 \mathrm{mmol})$ followed by $\mathrm{N}$ methyloxetan-3-amine $(81 \mu \mathrm{L}, 0.979 \mathrm{~g} / \mathrm{mL}, 0.91 \mathrm{mmol})$. The mixture was stirred at room temperature overnight then DBU $(0.338 \mathrm{~mL}, 1.019 \mathrm{~g} / \mathrm{mL}, 2.262 \mathrm{mmol})$ was added. The reaction was heated to 70 ${ }^{\circ} \mathrm{C}$ for $5 \mathrm{~h}$ then concentrated and purified by column chromatography $(0-10 \% \mathrm{MeOH} / \mathrm{DCM})$ to provide the title compound as a white solid (213 mg, 91\% yield). ${ }^{1} \mathrm{H}$ NMR (400 MHz, Methanol- $\left.d_{4}\right) \delta 7.50(\mathrm{~d}, J$ $=8.3 \mathrm{~Hz}, 1 \mathrm{H}), 7.34(\mathrm{~d}, J=7.5 \mathrm{~Hz}, 1 \mathrm{H}), 7.24(\mathrm{t}, J=7.9 \mathrm{~Hz}, 1 \mathrm{H}), 7.15(\mathrm{~s}, 1 \mathrm{H}), 4.69(\mathrm{dd}, J=12.8,1.5$ $\mathrm{Hz}, 1 \mathrm{H}), 4.30(\mathrm{dd}, J=12.8,4.7 \mathrm{~Hz}, 1 \mathrm{H}), 3.99-3.89(\mathrm{~m}, 1 \mathrm{H}), 3.73(\mathrm{dd}, J=11.2,5.2 \mathrm{~Hz}, 1 \mathrm{H}), 3.45$ $(\mathrm{dd}, J=11.1,8.4 \mathrm{~Hz}, 1 \mathrm{H}), 3.27(\mathrm{~s}, 3 \mathrm{H}) .{ }^{13} \mathrm{C}$ NMR $\left(101 \mathrm{MHz}, \mathrm{DMSO}-d_{6}\right) \delta 158.3,137.0,130.3,127.6$, 125.3, 123.5, 115.2, 111.0, 103.5, 59.7, 59.3, 41.0, 33.8. HRMS (ESI) m/z: $[\mathrm{M}+\mathrm{H}]^{+}$calculated for $\mathrm{C}_{13} \mathrm{H}_{13} \mathrm{BrN}_{2} \mathrm{O}_{2} \mathrm{H}^{+}$309.0239; found 309.0245. 


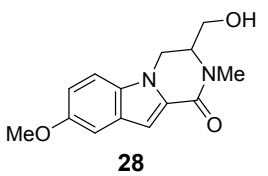

3-(hydroxymethyl)-8-methoxy-2-methyl-3,4-dihydropyrazino[1,2-a]indol-1(2H)-one. To a mixture of 5-methoxyindole-2-carboxylic acid $(182 \mathrm{mg}, 0.95 \mathrm{mmol})$ and HATU $(434 \mathrm{mg}, 1.14 \mathrm{mmol})$ in DMF $(3.2 \mathrm{~mL})$ was added $\mathrm{Et}_{3} \mathrm{~N}(0.27 \mathrm{~mL}, 0.728 \mathrm{~g} / \mathrm{mL}, 1.9 \mathrm{mmol})$ followed by N-methyloxetan-3amine $(0.10 \mathrm{~mL}, 0.979 \mathrm{~g} / \mathrm{mL}, 1.14 \mathrm{mmol})$. The mixture was stirred at room temperature overnight then DBU $(0.43 \mathrm{~mL}, 1.019 \mathrm{~g} / \mathrm{mL}, 2.86 \mathrm{mmol})$ was added. The reaction was heated to $70{ }^{\circ} \mathrm{C}$ for $24 \mathrm{~h}$ then concentrated and purified by column chromatography $(0-8 \% \mathrm{MeOH} / \mathrm{DCM})$ to afford the title compound as a white solid (227 mg, 92\% yield). ${ }^{1} \mathrm{H}$ NMR $\left(400 \mathrm{MHz}\right.$, Methanol- $\left.d_{4}\right) \delta 7.37$ (dd, $J=9.0$ $\mathrm{Hz}, 1 \mathrm{H}), 7.15(\mathrm{~d}, \mathrm{~J}=2.4 \mathrm{~Hz}, 1 \mathrm{H}), 7.08(\mathrm{~s}, 1 \mathrm{H}), 7.00(\mathrm{dd}, \mathrm{J}=9.0,2.4 \mathrm{~Hz}, 1 \mathrm{H}), 4.67-4.59(\mathrm{~m}, 1 \mathrm{H})$, $4.26-4.16(\mathrm{~m}, 1 \mathrm{H}), 3.94-3.86(\mathrm{~m}, 1 \mathrm{H}), 3.84(\mathrm{~s}, 3 \mathrm{H}), 3.72(\mathrm{dd}, J=11.0,5.3 \mathrm{~Hz}, 1 \mathrm{H}), 3.45(\mathrm{dd}, J=$ $11.0,8.6 \mathrm{~Hz}, 1 \mathrm{H}), 3.25(\mathrm{~s}, 3 \mathrm{H}) .{ }^{13} \mathrm{C}$ NMR $\left(101 \mathrm{MHz}, \mathrm{DMSO}-d_{6}\right) \delta 158.3,154.1,131.7,129.3,127.1$, 115.0, 111.5, 103.5, 102.4, 59.1, 59.0, 55.3, 40.1, 33.3. HRMS (ESI) m/z: $[\mathrm{M}+\mathrm{H}]^{+}$calculated for $\mathrm{C}_{14} \mathrm{H}_{16} \mathrm{~N}_{2} \mathrm{O}_{3} \mathrm{H}^{+}$261.1239; found 261.1247 .

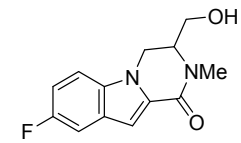

29

8-fluoro-3-(hydroxymethyl)-2-methyl-3,4-dihydropyrazino[1,2-a]indol-1(2H)-one. To a mixture of 5-fluoroindole-2-carboxylic acid $(180 \mathrm{mg}, 1.0 \mathrm{mmol})$ and HATU $(458 \mathrm{mg}, 1.2 \mathrm{mmol})$ in DMF $(3.4 \mathrm{~mL})$ was added $\mathrm{Et}_{3} \mathrm{~N}(0.28 \mathrm{~mL}, 0.728 \mathrm{~g} / \mathrm{mL}, 2.0 \mathrm{mmol})$ followed by $\mathrm{N}$-methyloxetan-3-amine $(0.11 \mathrm{~mL}, 0.979 \mathrm{~g} / \mathrm{mL}, 1.2 \mathrm{mmol})$. The mixture was stirred at room temperature overnight then DBU $(0.45 \mathrm{~mL}, 1.019 \mathrm{~g} / \mathrm{mL}, 3.0 \mathrm{mmol})$ was added. The reaction was heated to $70{ }^{\circ} \mathrm{C}$ for $5 \mathrm{~h}$ then concentrated and purified by column chromatography $(0-10 \% \mathrm{MeOH} / \mathrm{DCM})$ to afford the title compound as a white solid $(246 \mathrm{mg}, 98 \%) .{ }^{1} \mathrm{H}$ NMR $\left(400 \mathrm{MHz}\right.$, Methanol- $\left.d_{4}\right) \delta 7.44(\mathrm{dd}, J=9.0,4.3$ $\mathrm{Hz}, 1 \mathrm{H}), 7.33(\mathrm{dd}, J=9.5,2.5 \mathrm{~Hz}, 1 \mathrm{H}), 7.15-7.07(\mathrm{~m}, 2 \mathrm{H}), 4.64(\mathrm{dd}, J=12.8,1.5 \mathrm{~Hz}, 1 \mathrm{H}), 4.22$ $(\mathrm{dd}, J=12.8,4.6 \mathrm{~Hz}, 1 \mathrm{H}), 3.94-3.85(\mathrm{~m}, 1 \mathrm{H}), 3.69(\mathrm{dd}, J=11.1,5.2 \mathrm{~Hz}, 1 \mathrm{H}), 3.42(\mathrm{dd}, J=11.1$, $8.5 \mathrm{~Hz}, 1 \mathrm{H}), 3.23(\mathrm{~s}, 3 \mathrm{H}) .{ }^{13} \mathrm{C}$ NMR $\left(101 \mathrm{MHz}\right.$, Methanol- $\left.d_{4}\right) \delta 159.9,159.4,157.1,133.7,129.7$, $127.5,127.4,113.1,112.9,111.0,110.9,106.1,105.9,104.8,104.7,59.9,59.5,40.0$, 33.0. HRMS (ESI) $\mathrm{m} / \mathrm{z}:[\mathrm{M}+\mathrm{H}]^{+}$calculated for $\mathrm{C}_{13} \mathrm{H}_{13} \mathrm{FN}_{2} \mathrm{O}_{2} \mathrm{H}^{+}$249.1039; found 249.1047.

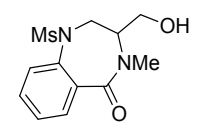

30

3-(hydroxymethyl)-4-methyl-1-(methylsulfonyl)-1,2,3,4-tetrahydro-5H-

benzo[e][1,4]diazepin-5-one. To a mixture of 2-(methylsulfonamido)benzoic acid (155 mg, 0.72 $\mathrm{mmol}$ ) and HATU (329 mg, $0.86 \mathrm{mmol})$ in DMF $(2.4 \mathrm{~mL})$ was added $\mathrm{Et}_{3} \mathrm{~N}(0.2 \mathrm{~mL}, 0.728 \mathrm{~g} / \mathrm{mL}, 1.44$ $\mathrm{mmol})$ followed by $\mathrm{N}$-methyloxetan-3-amine $(77 \mu \mathrm{L}, 0.979 \mathrm{~g} / \mathrm{mL}, 0.86 \mathrm{mmol})$. The mixture was stirred at room temperature overnight then DBU $(0.323 \mathrm{~mL}, 1.019 \mathrm{~g} / \mathrm{mL}, 2.16 \mathrm{mmol})$ was added. The reaction was heated to $70^{\circ} \mathrm{C}$ for $24 \mathrm{~h}$ then concentrated and purified by column chromatography (0$5 \% \mathrm{MeOH} / \mathrm{DCM}$ ) to afford the title compound as a colorless oil (153 mg, 75\% yield). ${ }^{1} \mathrm{H}$ NMR (400 $\mathrm{MHz}$, Chloroform- $d) \delta 7.75-7.68(\mathrm{~m}, 1 \mathrm{H}), 7.59-7.46(\mathrm{~m}, 3 \mathrm{H}), 4.23(\mathrm{dd}, \mathrm{J}=13.1,11.4 \mathrm{~Hz}, 1 \mathrm{H})$, $3.99-3.73(\mathrm{~m}, 3 \mathrm{H}), 3.69(\mathrm{dd}, J=13.1,3.9 \mathrm{~Hz}, 1 \mathrm{H}), 3.25(\mathrm{~s}, 3 \mathrm{H}), 2.78(\mathrm{~s}, 3 \mathrm{H}), 1.66(\mathrm{t}, J=5.1 \mathrm{~Hz}$, $1 \mathrm{H}) .{ }^{13} \mathrm{C}$ NMR (101 MHz, Chloroform-d) $\delta 169.5,135.4,133.8,132.3,131.2,129.8,129.6,59.8$, 58.1, 52.8, 38.9, 28.7. HRMS (ESI) $\mathrm{m} / \mathrm{z}$ : $[\mathrm{M}+\mathrm{H}]^{+}$calculated for $\mathrm{C}_{12} \mathrm{H}_{16} \mathrm{~N}_{2} \mathrm{O}_{4} \mathrm{SH}^{+}$285.0909; found 285.0916 .

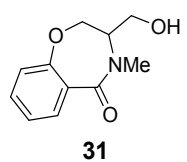


3-(hydroxymethyl)-4-methyl-3,4-dihydrobenzo[f][1,4]oxazepin-5(2H)-one. A mixture of salicylic acid $(228 \mathrm{mg}, 1.65 \mathrm{mmol})$ and CDI $(321 \mathrm{mg}, 1.98 \mathrm{mmol})$ in DMF $(5.3 \mathrm{~mL})$ was stirred at 70 ${ }^{\circ} \mathrm{C}$ for $2 \mathrm{~h}$ then $\mathrm{N}$-methyloxetan-3-amine $(176 \mu \mathrm{L}, 0.979 \mathrm{~g} / \mathrm{mL}, 1.98 \mathrm{mmol})$ was added and the mixture stirred overnight. DBU $(0.74 \mathrm{~mL}, 1.019 \mathrm{~g} / \mathrm{mL}, 4.952 \mathrm{mmol})$ was then added and the reaction was stirred at $70^{\circ} \mathrm{C}$ for $48 \mathrm{~h}$. The mixture was concentrated and purified by column chromatography $(0-10 \% \mathrm{MeOH} / \mathrm{DCM})$ to afford the title compound as a colorless oil (264 mg, yield $77 \%$ yield). ${ }^{1} \mathrm{H}$ NMR $(400 \mathrm{MHz}$, Chloroform-d) $\delta 8.29$ (dd, $J=8.1,1.7 \mathrm{~Hz}, 1 \mathrm{H}), 7.38(\mathrm{t}, J=7.6 \mathrm{~Hz}, 1 \mathrm{H}), 7.07(\mathrm{t}, J=7.6$ $\mathrm{Hz}, 1 \mathrm{H}), 6.99(\mathrm{~d}, J=8.2,1 \mathrm{H}), 4.72(\mathrm{dd}, J=12.6,5.1 \mathrm{~Hz}, 1 \mathrm{H}), 4.20(\mathrm{~d}, J=12.6 \mathrm{~Hz}, 1 \mathrm{H}), 3.88-3.67$ $(\mathrm{m}, 3 \mathrm{H}), 3.26(\mathrm{~s}, 3 \mathrm{H}), 1.95$ (bs, $1 \mathrm{H}) .{ }^{13} \mathrm{C}$ NMR $(101 \mathrm{MHz}$, Chloroform-d) $\delta 166.0,155.9,134.0,132.9$, $121.9,120.9,119.6,69.8,62.0,60.2,37.8$. HRMS (ESI) $\mathrm{m} / \mathrm{z}:[\mathrm{M}+\mathrm{H}]^{+}$calculated for $\mathrm{C}_{11} \mathrm{H}_{13} \mathrm{NO}_{3} \mathrm{H}^{+}$ 208.0974; found 208.0978 .

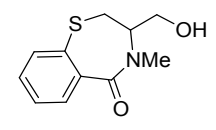

32

3-(hydroxymethyl)-4-methyl-3,4-dihydrobenzo[f][1,4]thiazepin-5(2H)-one. To a mixture of 2-mercaptobenzoic acid $(200 \mathrm{mg}, 1.30 \mathrm{mmol})$ and HATU $(592 \mathrm{mg}, 1.56 \mathrm{mmol})$ in DMF $(4.2 \mathrm{~mL})$ was added $\mathrm{Et}_{3} \mathrm{~N}(0.45 \mathrm{~mL}, 0.728 \mathrm{~g} / \mathrm{mL}, 3.24 \mathrm{mmol})$ followed by $\mathrm{N}$-methyloxetan-3-amine $(139 \mu \mathrm{L}, 0.979$ $\mathrm{g} / \mathrm{mL}, 1.56 \mathrm{mmol})$. The mixture was stirred at room temperature overnight then DBU $(0.58 \mathrm{~mL}, 1.019$ $\mathrm{g} / \mathrm{mL}, 3.89 \mathrm{mmol}$ ) was added. The reaction was heated to $70^{\circ} \mathrm{C}$ for $24 \mathrm{~h}$ then concentrated and purified by column chromatography $(0-10 \% \mathrm{MeOH} / \mathrm{DCM})$ to afford the title compound as an off-white solid (204 mg, 70\% yield). ${ }^{1} \mathrm{H}$ NMR (400 MHz, Chloroform- $d$ ) $\delta 7.63$ (dd, 7.4, $\left.1.4 \mathrm{~Hz}, 1 \mathrm{H}\right), 7.50-$ $7.35(\mathrm{~m}, 3 \mathrm{H}), 4.01-3.89(\mathrm{~m}, 1 \mathrm{H}), 3.85-3.69(\mathrm{~m}, 2 \mathrm{H}), 3.22-3.13(\mathrm{~m}, 4 \mathrm{H}), 3.20-2.90(\mathrm{~m}, 1 \mathrm{H})$, $1.82(\mathrm{~s}, 1 \mathrm{H}) .{ }^{13} \mathrm{C}$ NMR $\left(101 \mathrm{MHz}\right.$, Methanol- $\left.d_{4}\right) \delta 171.7,141.1,133.6,131.1,129.1,128.9,128.7$, 60.2, 58.8, 34.6, 26.1. HRMS (ESI) $\mathrm{m} / \mathrm{z}:[\mathrm{M}+\mathrm{H}]^{+}$calculated for $\mathrm{C}_{11} \mathrm{H}_{13} \mathrm{NO}_{2} \mathrm{SH}^{+} 224.0745$; found 224.0751 .

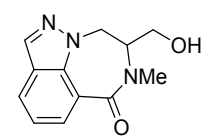

33

8-(hydroxymethyl)-7-methyl-8,9-dihydro-[1,4]diazepino[6,7,1-hi]indazol-6(7H)-one. To a solution of $1 \mathrm{H}$-indazole-7-carboxylic acid $(173 \mathrm{mg}, 1.1 \mathrm{mmol})$ and HATU $(487 \mathrm{mg}, 1.3 \mathrm{mmol})$ in DMF $(3.6 \mathrm{~mL})$ was added $\mathrm{Et}_{3} \mathrm{~N}(0.30 \mathrm{~mL}, 0.728 \mathrm{~g} / \mathrm{mL}, 2.1 \mathrm{mmol})$ followed by $\mathrm{N}$-methyloxetan-3-amine $(0.13 \mathrm{~mL}, 0.979 \mathrm{~g} / \mathrm{mL}, 1.5 \mathrm{mmol})$. The mixture was stirred overnight then $\mathrm{Cs}_{2} \mathrm{CO}_{3}(1043 \mathrm{mg}, 3.2$ $\mathrm{mmol}$ ) was added to and the mixture heated at $70^{\circ} \mathrm{C}$ for $5 \mathrm{~h}$. The mixture was diluted with EtOAc and water. The organics were extracted with EtOAc (5x), dried over sodium sulfate, filtered and concentrated. Purification by column chromatography (60-80\% EtOAc/heptane) afforded the title compound as a white solid ( $223 \mathrm{mg}, 90 \%$ yield). ${ }^{1} \mathrm{H}$ NMR $(400 \mathrm{MHz}$, Chloroform-d) $\delta 8.33$ (dd, $J=$ $7.5,1.2 \mathrm{~Hz}, 1 \mathrm{H}), 8.05(\mathrm{~s}, 1 \mathrm{H}), 7.90(\mathrm{~d}, \mathrm{~J}=8.0 \mathrm{~Hz}, 1 \mathrm{H}), 7.33-7.26(\mathrm{~m}, 1 \mathrm{H}), 5.06(\mathrm{dd}, \mathrm{J}=14.1,4.7$ $\mathrm{Hz}, 1 \mathrm{H}), 4.66(\mathrm{dd}, J=14.1,1.8 \mathrm{~Hz}, 1 \mathrm{H}), 4.17-4.06(\mathrm{~m}, 1 \mathrm{H}), 3.66-3.53(\mathrm{~m}, 1 \mathrm{H}), 3.50-3.35(\mathrm{~m}$, $4 \mathrm{H}), 1.92(\mathrm{~s}, 1 \mathrm{H}) .{ }^{13} \mathrm{C}$ NMR $(101 \mathrm{MHz}$, Chloroform-d) $\delta 165.8,135.3,134.0,131.9,125.4,124.9$, $121.2,115.9,61.6,60.8,51.6,39.9$. HRMS (ESI) $\mathrm{m} / \mathrm{z}$ : $[\mathrm{M}+\mathrm{H}]^{+}$calculated for $\mathrm{C}_{12} \mathrm{H}_{13} \mathrm{~N}_{3} \mathrm{O}_{2} \mathrm{H}^{+}$ 232.1086; found 232.1090 .

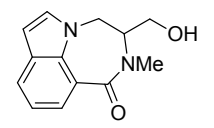

34

3-(hydroxymethyl)-2-methyl-3,4-dihydro-[1,4]diazepino[6,7,1-hi]indol-1(2H)-one. To a mixture of $1 \mathrm{H}$-indole-7-carboxylic acid $(198 \mathrm{mg}, 1.23 \mathrm{mmol})$ and HATU $(561 \mathrm{mg}, 1.47 \mathrm{mmol})$ in DMF $(4.1 \mathrm{~mL})$ was added $\mathrm{Et}_{3} \mathrm{~N}(0.34 \mathrm{~mL}, 0.728 \mathrm{~g} / \mathrm{mL}, 2.5 \mathrm{mmol})$ followed by $\mathrm{N}$-methyloxetan-3-amine $(0.13 \mathrm{~mL}, 0.979 \mathrm{~g} / \mathrm{mL}, 1.47 \mathrm{mmol})$. The mixture was stirred at room temperature overnight then $\mathrm{Cs}_{2} \mathrm{CO}_{3}(1201 \mathrm{mg}, 3.69 \mathrm{mmol})$ was added. The reaction was heated to $70^{\circ} \mathrm{C}$ for $24 \mathrm{~h}$ then filtered over a plug of celite. Purification by column chromatography $(0-10 \% \mathrm{MeOH} / \mathrm{DCM})$ then washing the solid with ether provided the title compound as a white solid $(240 \mathrm{mg}, 85 \%$ yield $) .{ }^{1} \mathrm{H}$ NMR $(400 \mathrm{MHz}$, Chloroform-d) $\delta 8.16(\mathrm{~d}, J=7.6 \mathrm{~Hz}, 1 \mathrm{H}), 7.77(\mathrm{~d}, J=7.8 \mathrm{~Hz}, 1 \mathrm{H}), 7.21(\mathrm{t}, J=7.6 \mathrm{~Hz}, 1 \mathrm{H}), 7.06(\mathrm{~d}, J$ 
$=3.0 \mathrm{~Hz}, 1 \mathrm{H}), 6.59(\mathrm{~d}, J=3.0 \mathrm{~Hz}, 1 \mathrm{H}), 4.64(\mathrm{dd}, J=13.7,4.9 \mathrm{~Hz}, 1 \mathrm{H}), 4.45(\mathrm{~d}, J=13.7 \mathrm{~Hz}, 1 \mathrm{H})$, $4.08-3.98(\mathrm{~m}, 1 \mathrm{H}), 3.64-3.54(\mathrm{~m}, 1 \mathrm{H}), 3.45-3.35(\mathrm{~m}, 4 \mathrm{H}), 1.65-1.59(\mathrm{~m}, 1 \mathrm{H}) .{ }^{13} \mathrm{C}$ NMR $(101$ $\mathrm{MHz}$, Methanol- $\left.d_{4}\right) \delta 167.6,132.1,129.9,129.1,126.0,124.8,118.8,116.7,101.6,62.4,59.5,49.0$, 38.8. HRMS (ESI) $\mathrm{m} / \mathrm{z}$ : $[\mathrm{M}+\mathrm{H}]^{+}$calculated for $\mathrm{C}_{13} \mathrm{H}_{14} \mathrm{~N}_{2} \mathrm{O}_{2} \mathrm{H}^{+}$231.1134; found 231.1142.

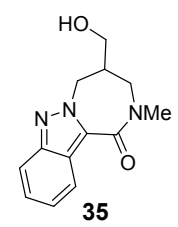

4-(hydroxymethyl)-2-methyl-2,3,4,5-tetrahydro-1H-[1,4]diazepino[1,2-b]indazol-1-one. To a solution of indazole-3-carboxylic acid $(135 \mathrm{mg}, 0.83 \mathrm{mmol})$ and HATU $(380 \mathrm{mg}, 1.0 \mathrm{mmol})$ in DMF $(2.9 \mathrm{~mL})$ was added $\mathrm{Et}_{3} \mathrm{~N}(0.23 \mathrm{~mL}, 0.728 \mathrm{~g} / \mathrm{mL}, 1.67 \mathrm{mmol})$ followed by N-methyl-1-(oxetan-3$\mathrm{yl})$ methanamine $(126 \mathrm{mg}, 1.25 \mathrm{mmol})$. The mixture was stirred overnight then $\mathrm{Cs}_{2} \mathrm{CO}_{3}(814 \mathrm{mg}, 2.5$ $\mathrm{mmol}$ ) was added and the mixture stirred at $70^{\circ} \mathrm{C}$ for $24 \mathrm{~h}$. The reaction was then diluted with EtOAc and water and transferred to a separatory funnel. The organics were extracted $(3 \mathrm{x})$, dried over sodium sulfate, filtered and concentrated. Purification by column chromatography $(70-100 \%$ EtOAc/heptane) afforded P1 as a colorless oil (178 mg, 87\% yield). ${ }^{1} \mathrm{H}$ NMR (400 MHz, Chloroform- $d$ ) $\delta 7.94(\mathrm{~d}, J=8.4 \mathrm{~Hz}, 1 \mathrm{H}), 7.71(\mathrm{~d}, J=8.7 \mathrm{~Hz}, 1 \mathrm{H}), 7.35(\mathrm{dd}, J=8.3,7.0 \mathrm{~Hz}, 1 \mathrm{H}), 7.26-7.19(\mathrm{~m}$, $1 \mathrm{H}), 4.74(\mathrm{dd}, J=14.0,6.8 \mathrm{~Hz}, 1 \mathrm{H}), 4.60(\mathrm{dd}, J=14.1,5.0 \mathrm{~Hz}, 1 \mathrm{H}), 3.76-3.65(\mathrm{~m}, 2 \mathrm{H}), 3.44(\mathrm{dd}$, $J=15.0,5.9 \mathrm{~Hz}, 1 \mathrm{H}), 3.35-3.22(\mathrm{~m}, 4 \mathrm{H}), 2.97-2.77(\mathrm{~m}, 1 \mathrm{H}), 2.14(\mathrm{t}, J=4.8 \mathrm{~Hz}, 1 \mathrm{H}) .{ }^{13} \mathrm{C} \mathrm{NMR}$ (101 MHz, Chloroform-d) $\delta 163.0,147.6,129.3,126.8,124.1,123.0,120.5,117.3,61.9,51.6,49.9$, 43.6, 35.7. HRMS (ESI) m/z: [M+H] ${ }^{+}$calculated for $\mathrm{C}_{13} \mathrm{H}_{15} \mathrm{~N}_{3} \mathrm{O}_{2} \mathrm{H}^{+}$246.1243; found 246.1253.

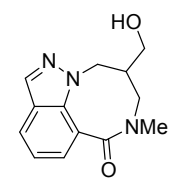

36

9-(hydroxymethyl)-7-methyl-7,8,9,10-tetrahydro-6H-[1,5]diazocino[3,2,1-hi] indazol-6one. To a solution of $1 \mathrm{H}$-indazole-7-carboxylic acid $(190 \mathrm{mg}, 1.17 \mathrm{mmol})$ and HATU $(535 \mathrm{mg}, 1.41$ $\mathrm{mmol})$ in DMF $(3.9 \mathrm{~mL})$ was added $\mathrm{Et}_{3} \mathrm{~N}(0.33 \mathrm{~mL}, 0.728 \mathrm{~g} / \mathrm{mL}, 2.34 \mathrm{mmol})$ followed by N-methyl-1(oxetan-3-yl)methanamine $\left(142 \mathrm{mg}, 1.406 \mathrm{mmol}\right.$ ). The mixture was stirred overnight then $\mathrm{Cs}_{2} \mathrm{CO}_{3}$ $\left(1145 \mathrm{mg}, 3.52 \mathrm{mmol}\right.$ ) was added and the mixture heated to $100^{\circ} \mathrm{C}$ for $24 \mathrm{~h}$. The crude mixture was filtered, concentrated and purified by column chromatography (2-8\% MeOH/DCM) to afford the title compound as a white solid (209 mg, $72 \%$ yield). ${ }^{1} \mathrm{H}$ NMR $\left(400 \mathrm{MHz}\right.$, Methanol- $\left.d_{4}\right) \delta 8.07(\mathrm{~s}, 1 \mathrm{H}), 7.92$ $(\mathrm{dd}, J=8.1,1.0 \mathrm{~Hz}, 1 \mathrm{H}), 7.72(\mathrm{dd}, J=7.2,1.0 \mathrm{~Hz}, 1 \mathrm{H}), 7.30-7.21(\mathrm{~m}, 1 \mathrm{H}), 4.72(\mathrm{~d}, J=15.0 \mathrm{~Hz}$, $1 \mathrm{H}), 4.48(\mathrm{dd}, J=15.1,3.4 \mathrm{~Hz}, 1 \mathrm{H}), 3.49-3.36(\mathrm{~m}, 2 \mathrm{H}), 3.27-3.17(\mathrm{~m}, 6 \mathrm{H}) .{ }^{13} \mathrm{C} \mathrm{NMR}(101 \mathrm{MHz}$, Chloroform-d) $\delta 168.2,137.3,133.2,129.8,124.5,124.0,121.2,118.6,61.1,49.8,47.6,38.2$, 34.2. HRMS (ESI) $\mathrm{m} / \mathrm{z}$ : $[\mathrm{M}+\mathrm{H}]^{+}$calculated for $\mathrm{C}_{13} \mathrm{H}_{15} \mathrm{~N}_{3} \mathrm{O}_{2} \mathrm{H}^{+}$246.1243; found 246.1249.

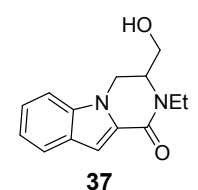

2-ethyl-3-(hydroxymethyl)-3,4-dihydropyrazino[1,2-a]indol-1(2H)-one. $1 \mathrm{H}$-indole-2carboxylic acid $(173 \mathrm{mg}, 1.07 \mathrm{mmol})$ and HATU $(490 \mathrm{mg}, 1.29 \mathrm{mmol})$ in DMF $(3.6 \mathrm{~mL})$ was added $\mathrm{Et}_{3} \mathrm{~N}(0.30 \mathrm{~mL}, 0.728 \mathrm{~g} / \mathrm{mL}, 2.15 \mathrm{mmol})$ followed by $\mathrm{N}$-ethyloxetan-3-amine $(130 \mathrm{mg}, 1.289 \mathrm{mmol})$. The mixture was stirred at room temperature overnight then DBU $(0.48 \mathrm{~mL}, 1.019 \mathrm{~g} / \mathrm{mL}, 3.22 \mathrm{mmol})$ was added and the mixture heated to $70^{\circ} \mathrm{C}$ for $24 \mathrm{~h}$. The reaction mixture was diluted with EtOAc and water. The organics were extracted with EtOAc $(3 \mathrm{x})$. The combined organic layers were washed with brine, dried over sodium sulfate, filtered and concentrated. Purification by column chromatography (0$10 \% \mathrm{MeOH} / \mathrm{DCM}$ ) afforded the title compound as a white solid $\left(210 \mathrm{mg}, 80 \%\right.$ yield). ${ }^{1} \mathrm{H}$ NMR (400 $\mathrm{MHz}$, Methanol- $\left.d_{4}\right) \delta 7.68(\mathrm{~d}, J=8.1 \mathrm{~Hz}, 1 \mathrm{H}), 7.48(\mathrm{~d}, J=8.4 \mathrm{~Hz}, 1 \mathrm{H}), 7.34(\mathrm{t}, J=7.7 \mathrm{~Hz}, 1 \mathrm{H}), 7.17$ - $7.11(\mathrm{~m}, 2 \mathrm{H}), 4.75(\mathrm{~d}, J=12.7 \mathrm{~Hz}, 1 \mathrm{H}), 4.23-4.06(\mathrm{~m}, 2 \mathrm{H}), 3.96(\mathrm{~m}, 1 \mathrm{H}), 3.68(\mathrm{dd}, J=11.0,5.0$ $\mathrm{Hz}, 1 \mathrm{H}), 3.40(\mathrm{dd}, J=10.9,9.2 \mathrm{~Hz}, 1 \mathrm{H}), 3.27(\mathrm{~m}, 1 \mathrm{H}), 1.32(\mathrm{t}, J=7.2 \mathrm{~Hz}, 3 \mathrm{H}) .{ }^{13} \mathrm{C} \mathrm{NMR}(101 \mathrm{MHz}$, 
Chloroform-d) $\delta 159.0,136.8,128.8,127.5,124.4,122.6,120.6,109.6,105.9,60.6,56.9,40.8$, 40.6, 13.9. HRMS (ESI) m/z: $[\mathrm{M}+\mathrm{H}]^{+}$calculated for $\mathrm{C}_{14} \mathrm{H}_{16} \mathrm{~N}_{2} \mathrm{O}_{2} \mathrm{H}^{+}$245.1290; found 245.1299.<smiles>CN(Cc1[nH]nc2ccccc12)C1COC1</smiles>

38

N-((2H-indazol-3-yl)methyl)-N-methyloxetan-3-amine. A mixture of $1 \mathrm{H}$-indazole-3carbaldehyde $(215 \mathrm{mg}, 1.47 \mathrm{mmol})$ and $\mathrm{N}$-methyloxetan-3-amine (154 mg, $1.77 \mathrm{mmol})$ in DCM was stirred for 15 minutes at room temperature then $\mathrm{Et}_{3} \mathrm{~N}(0.61 \mathrm{~mL}, 0.728 \mathrm{~g} / \mathrm{mL}, 4.41 \mathrm{mmol})$ and sodium triacetoxylborohydride $(935 \mathrm{mg}, 4.41 \mathrm{mmol}$ ) were added. The mixture was stirred for $3 \mathrm{~h}$ then quenched with water. The organics were extracted with DCM, washed with brine, dried over sodium sulfate, filtered and concentrated. The crude material was purified by column chromatography (0-10\% $\mathrm{MeOH} / \mathrm{EtOAc}$ ) to provide the title compound as a pale yellow solid (202 mg, 63\% yield). ${ }^{1} \mathrm{H} \mathrm{NMR}$ (400 $\mathrm{MHz}$, Chloroform-d) $\delta 9.89(\mathrm{~s}, 1 \mathrm{H}), 7.91(\mathrm{~d}, \mathrm{~J}=8.1 \mathrm{~Hz}, 1 \mathrm{H}), 7.56-7.32(\mathrm{~m}, 2 \mathrm{H}), 7.20(\mathrm{t}, \mathrm{J}=7.4 \mathrm{~Hz}$, $1 \mathrm{H}), 4.73-4.55(\mathrm{~m}, 4 \mathrm{H}), 3.81(\mathrm{~s}, 2 \mathrm{H}), 3.75(\mathrm{p}, \mathrm{J}=6.6 \mathrm{~Hz}, 1 \mathrm{H}), 2.17(\mathrm{~s}, 3 \mathrm{H}) .{ }^{13} \mathrm{C} \mathrm{NMR}(101 \mathrm{MHz}$, Chloroform-d) $\delta 143.3,141.1,126.9,122.5,120.8,120.7,109.8,76.2,59.2,51.2,38.7$. HRMS (ESI) $\mathrm{m} / \mathrm{z}:[\mathrm{M}+\mathrm{H}]^{+}$calculated for $\mathrm{C}_{12} \mathrm{H}_{15} \mathrm{~N}_{3} \mathrm{OH}^{+}$218.1293; found 218.1308.

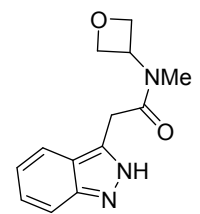

39

2-(2H-indazol-3-yl)-N-methyl-N-(oxetan-3-yl)acetamide. To a mixture of 2-(1H-indazol-3$\mathrm{yl}$ )acetic acid (150 mg, $0.85 \mathrm{mmol})$ and HATU $(356 \mathrm{mg}, 0.94 \mathrm{mmol})$ in DMF (1.0 mL) was added $\mathrm{N}-$ methyloxetan-3-amine $0.91 \mu \mathrm{L}, 0.979 \mathrm{~g} / \mathrm{mL}, 1.02 \mathrm{mmol})$ and $\mathrm{Et}_{3} \mathrm{~N}(0.24 \mathrm{~mL}, 0.728 \mathrm{~g} / \mathrm{mL}, 1.70$ $\mathrm{mmol}$ ). The mixture was stirred at room temperature overnight then concentrated to an orange oil. Purification of the crude residue by column chromatography (0-10\% MeOH/DCM) yielded the title compound as an orange oil (208 mg, 99\% yield). Mixture of rotamers. $1 \mathrm{H}$ and $13 \mathrm{C}$ NMR peaks not assigned due to ambiguous spectra (vide infra). HRMS (ESI) m/z: $[\mathrm{M}+\mathrm{H}]^{+}$calculated for $\mathrm{C}_{13} \mathrm{H}_{15} \mathrm{~N}_{3} \mathrm{O}_{2} \mathrm{H}^{+}$ 246.1243; found 246.1249.

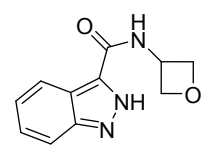

40

N-(oxetan-3-yl)-2H-indazole-3-carboxamide. To a solution of indazole-3-carboxylic acid (51 mg, $0.32 \mathrm{mmol})$ and HATU $(145 \mathrm{mg}, 0.38 \mathrm{mmol})$ in DMF was added $\mathrm{Et}_{3} \mathrm{~N}(87 \mu \mathrm{L}, 0.728 \mathrm{~g} / \mathrm{mL}, 0.63 \mathrm{mmol})$ followed by 3-oxetaneamine $(26 \mu \mathrm{L}, 1.042 \mathrm{~g} / \mathrm{mL}, 0.38 \mathrm{mmol})$. The mixture was stirred at room temperature overnight then DBU $(0.14 \mathrm{~mL}, 1.019 \mathrm{~g} / \mathrm{mL}, 0.94 \mathrm{mmol})$ was added. The reaction was heated to $70{ }^{\circ} \mathrm{C}$ for $24 \mathrm{~h}$ then concentrated. Trace cyclized product observed. The title compound was purified by column chromatography $(0-10 \% \mathrm{MeOH} / \mathrm{DCM})$ to yield a white solid (51 mg, $74 \% \mathrm{yield}) .{ }^{1} \mathrm{H}$ NMR (400 MHz, Methanol- $\left.d_{4}\right) \delta 8.18(\mathrm{~d}, J=8.2 \mathrm{~Hz}, 1 \mathrm{H}), 7.58(\mathrm{~d}, J=8.5 \mathrm{~Hz}, 1 \mathrm{H}), 7.47-7.37(\mathrm{t}, \mathrm{J}=$ $7.5 \mathrm{~Hz}, 1 \mathrm{H}), 7.25(\mathrm{t}, J=7.5 \mathrm{~Hz}, 1 \mathrm{H}), 5.23(\mathrm{p}, J=7.0 \mathrm{~Hz}, 1 \mathrm{H}), 4.95(\mathrm{t}, J=7.0 \mathrm{~Hz}, 2 \mathrm{H}), 4.79(\mathrm{t}, J=$ $6.6 \mathrm{~Hz}, 2 \mathrm{H}) .{ }^{13} \mathrm{C}$ NMR $(101 \mathrm{MHz}$, Methanol-d 4$) \delta 163.6,141.5,137.6,126.5,122.1,121.7,121.2$, 110.1, 77.9, 44.3. HRMS (ESI) m/z: $[\mathrm{M}+\mathrm{H}]^{+}$calculated for $\mathrm{C}_{11} \mathrm{H}_{11} \mathrm{~N}_{3} \mathrm{O}_{2} \mathrm{H}^{+}$218.0930; found 218.0934 .<smiles>OCC1COc2ccccc2O1</smiles>

(2,3-dihydrobenzo[b][1,4]dioxin-2-yl)methanol. A mixture of catechol (110 mg, $1 \mathrm{mmol}), 3-$ iodooxetane $(0.1 \mathrm{~mL}, 2.09 \mathrm{~g} / \mathrm{mL}, 1.1 \mathrm{mmol})$ and $\mathrm{Cs}_{2} \mathrm{CO}_{3}(977 \mathrm{mg}, 3 \mathrm{mmol})$ were stirred in DMF (2 $\mathrm{mL})$ at $80{ }^{\circ} \mathrm{C}$ for $16 \mathrm{~h}$ then concentrated. Purification by column chromatography (5-20\% 
EtOAc/heptane) afforded the title compound (125 mg, 75\% yield). Spectroscopic data matched that previously reported in literature. ${ }^{2}$

${ }^{1}$ Kuduk, S.; Hartman, G. D. Oxadiazepinone derivatives and their use in the treatment of hepatitis B infections. WO 2018/005881 A1, January $4^{\text {th }}, 2018$.

2 Wang, S.; Chen, Y.; Zhao, S.; Xu, X.; Liu, X.; Liu, B.-F.; Zhang, G. Bioorganic and Medicinal Chemistry Letters, 2014, 7, 1766-1770. 


\section{NMR Spectra}

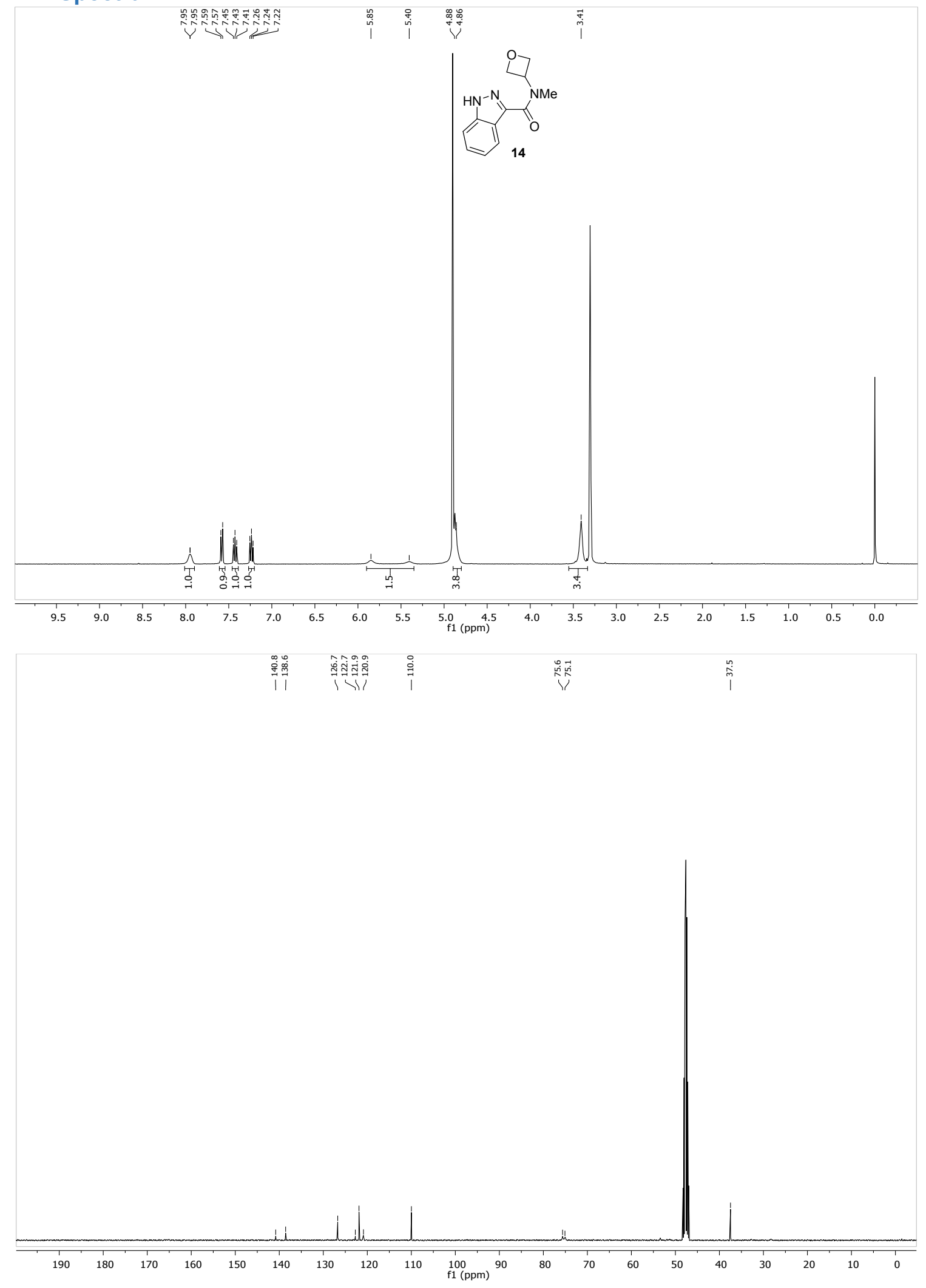




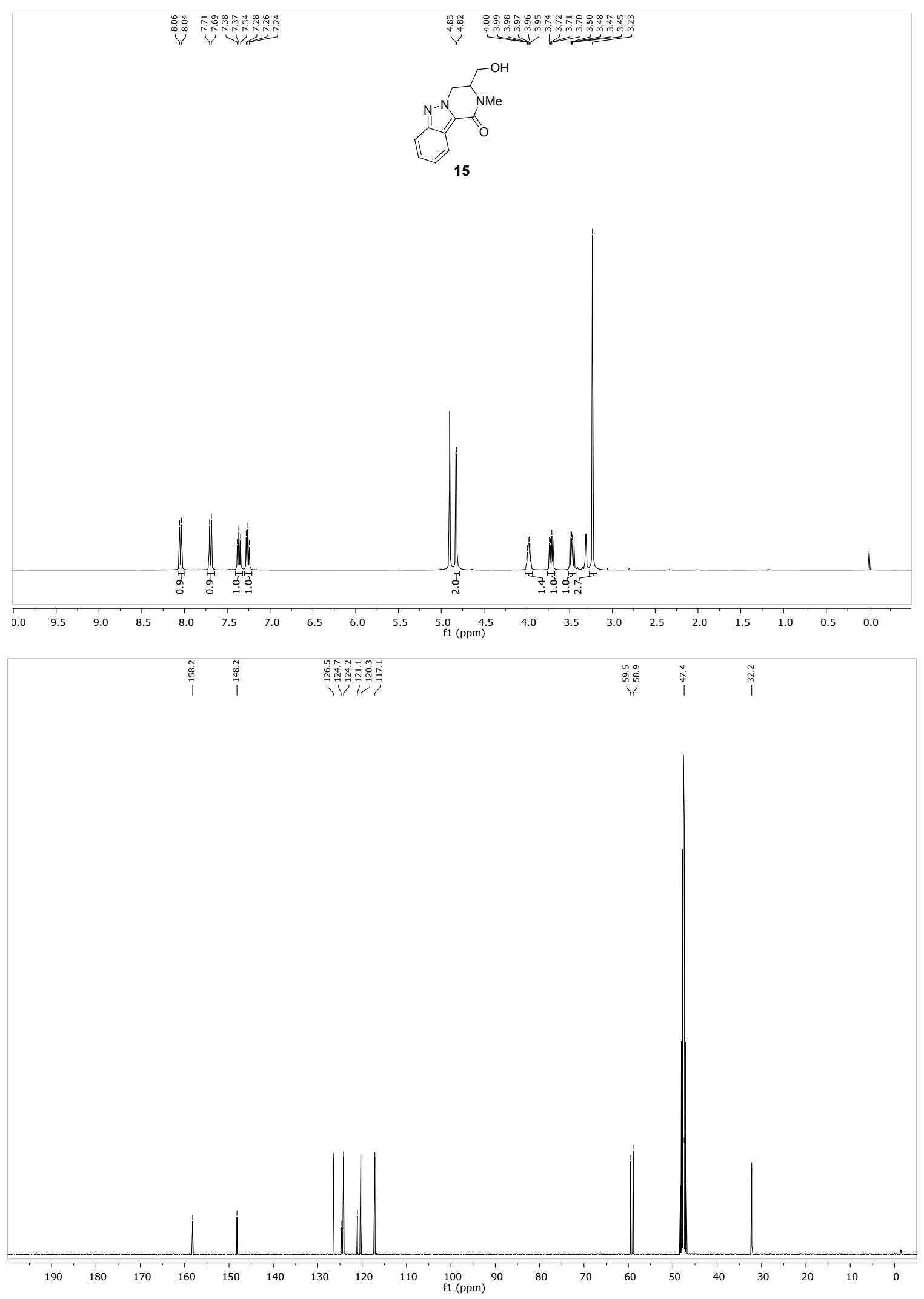



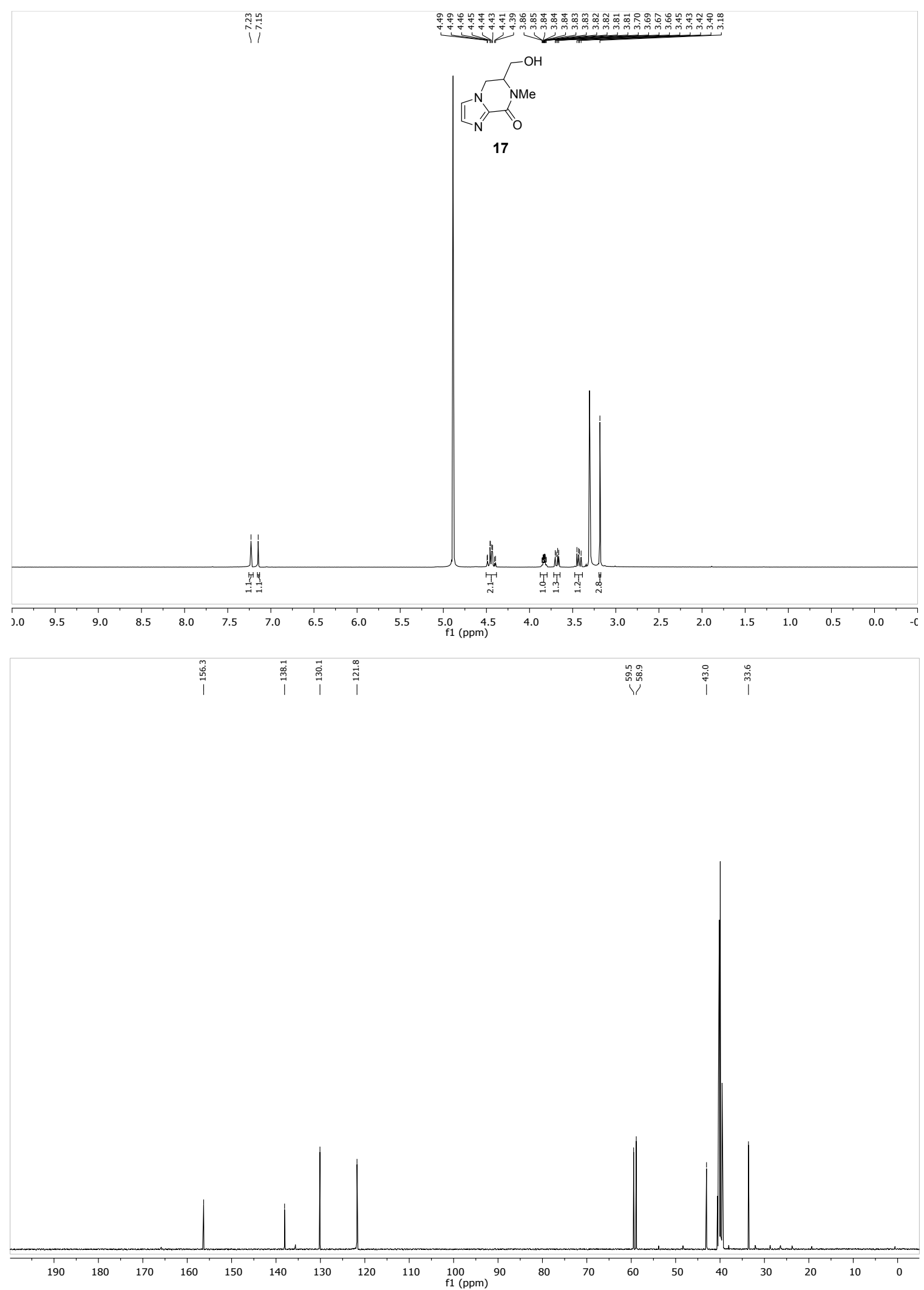

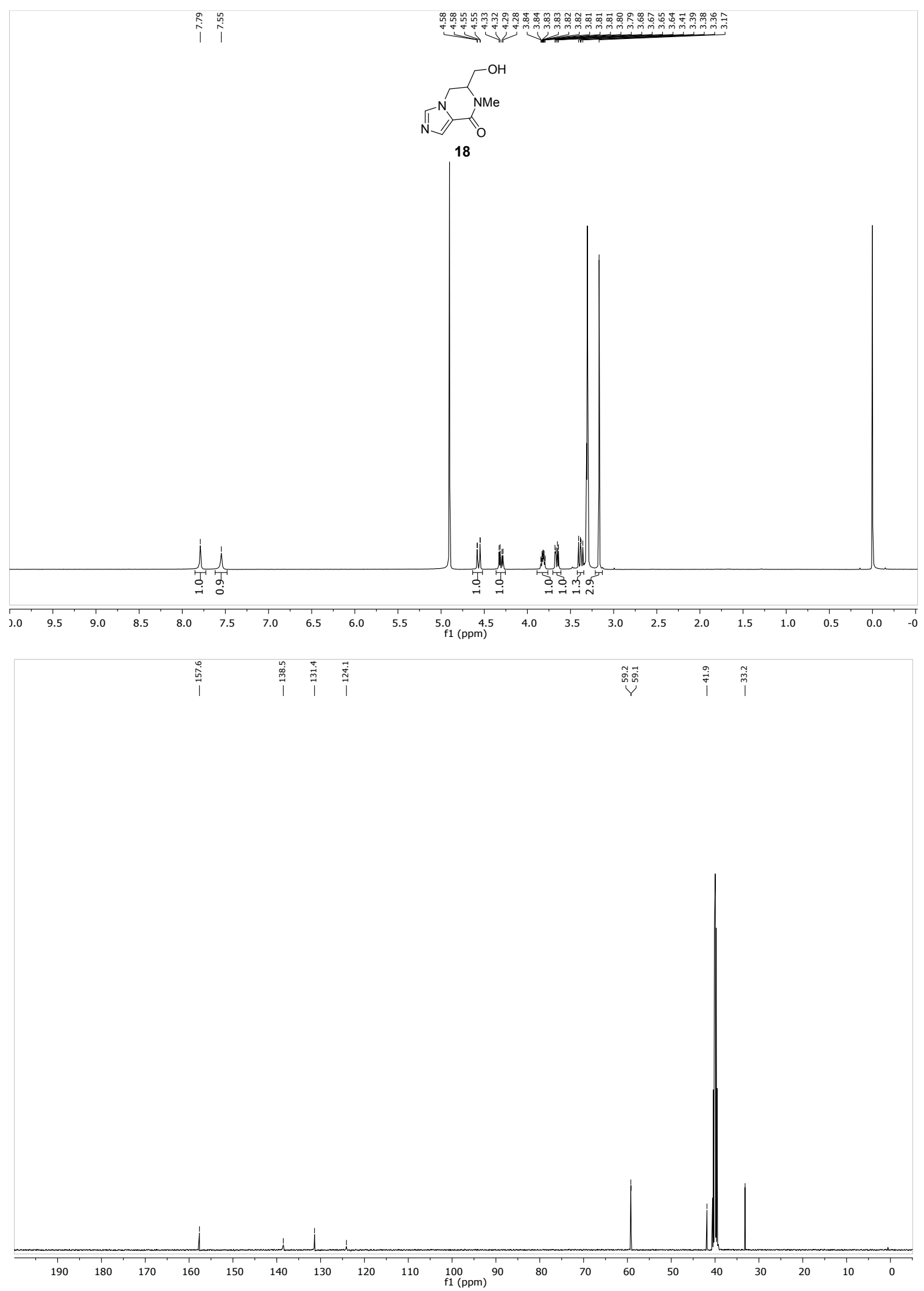

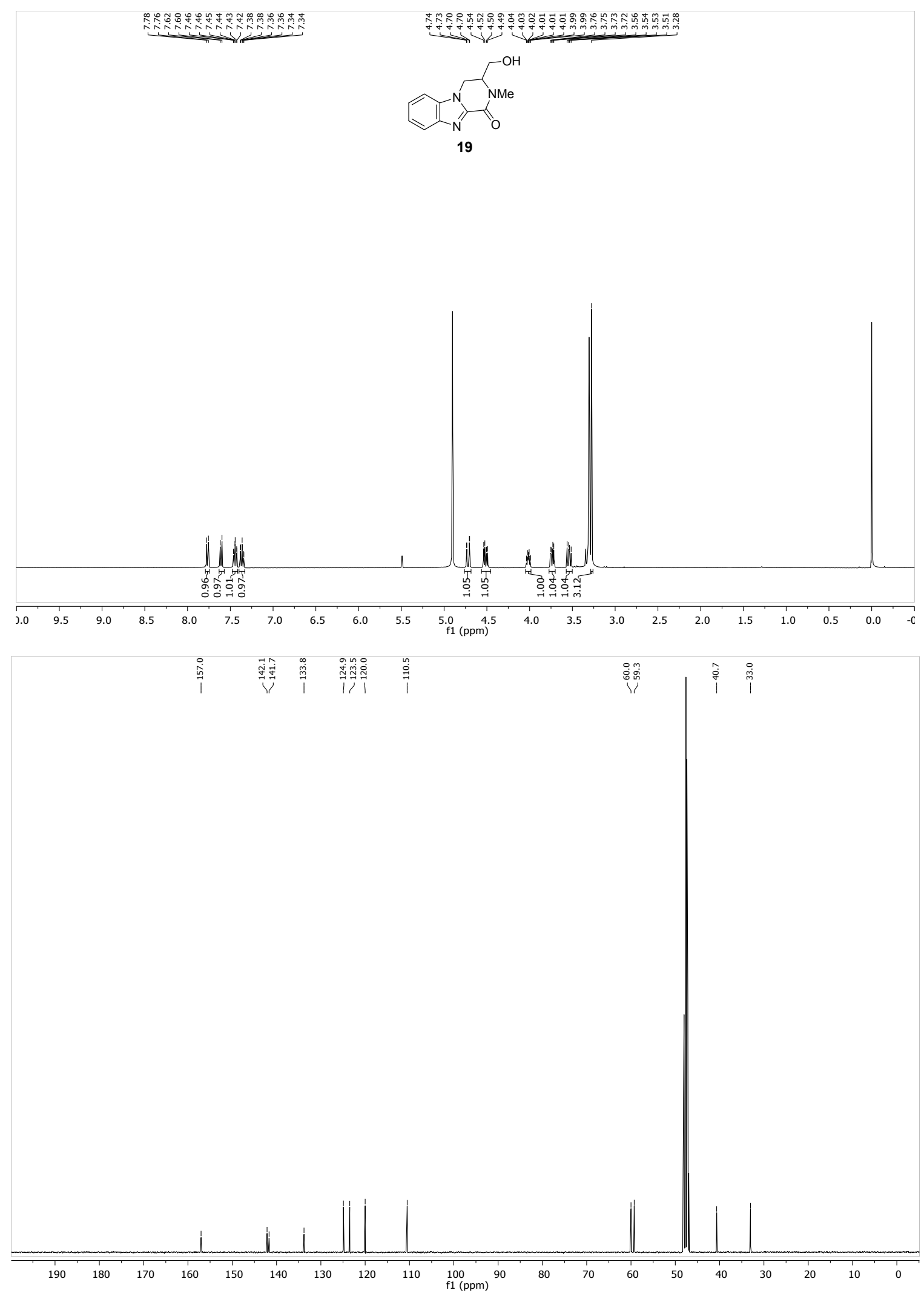

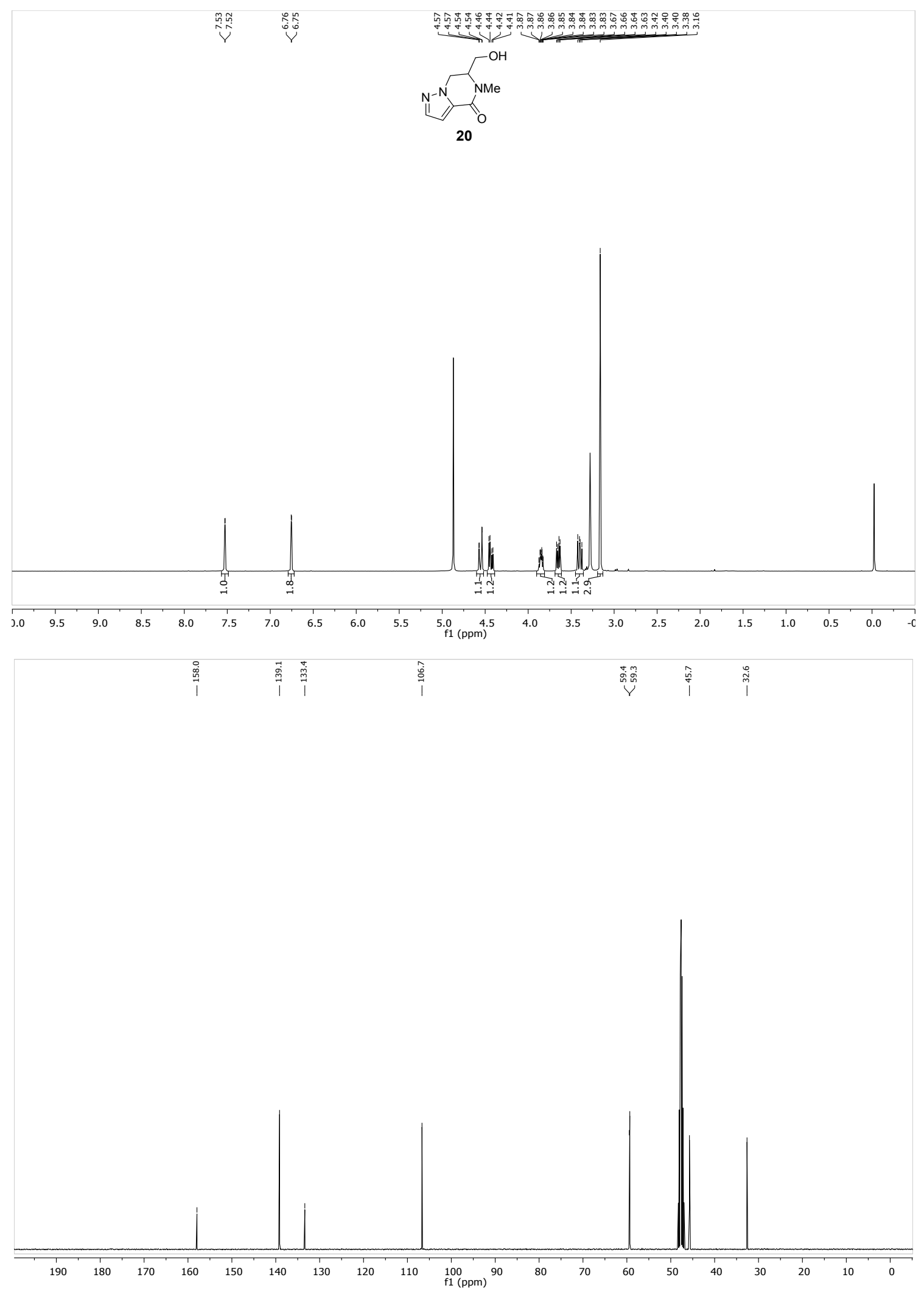


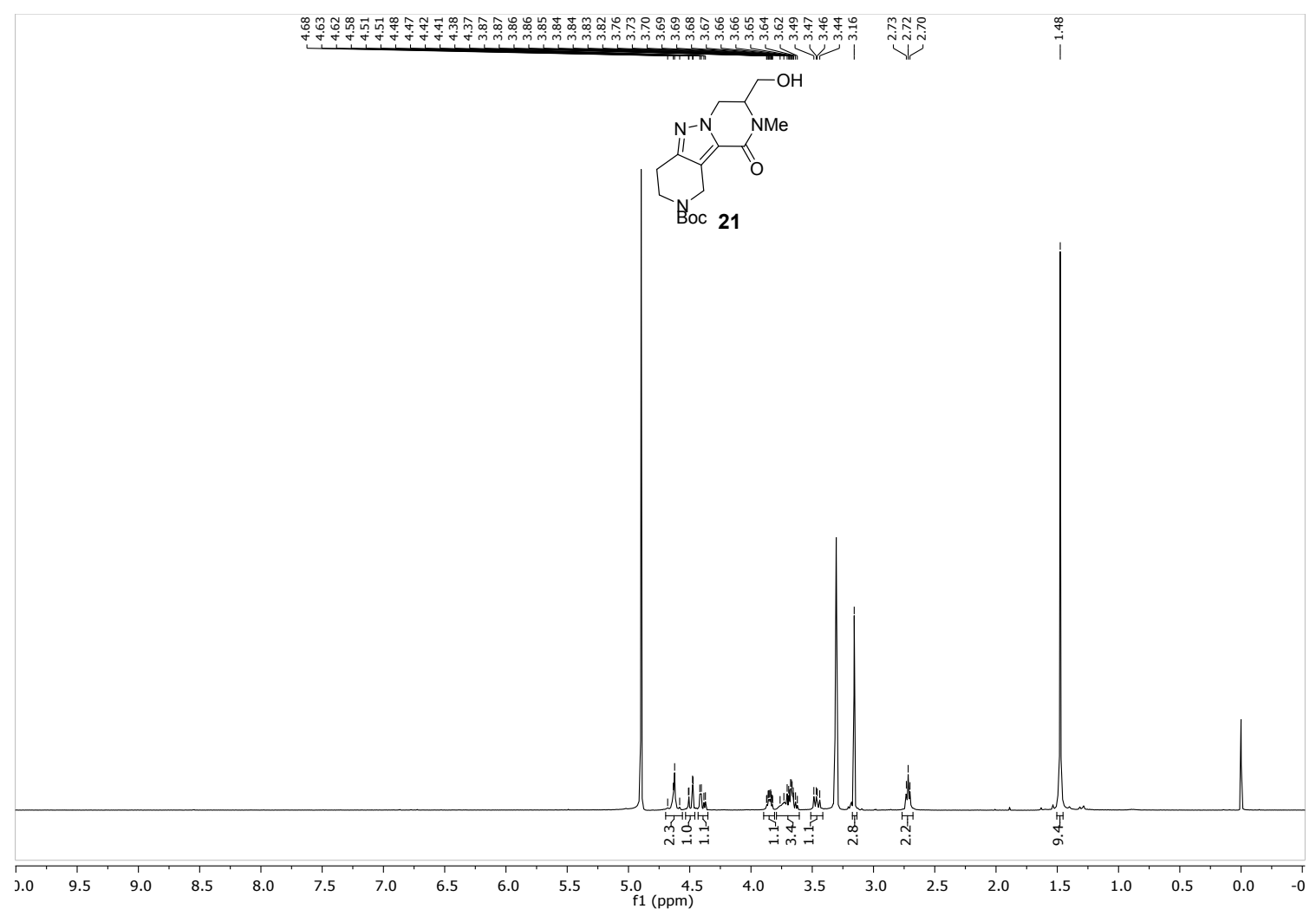



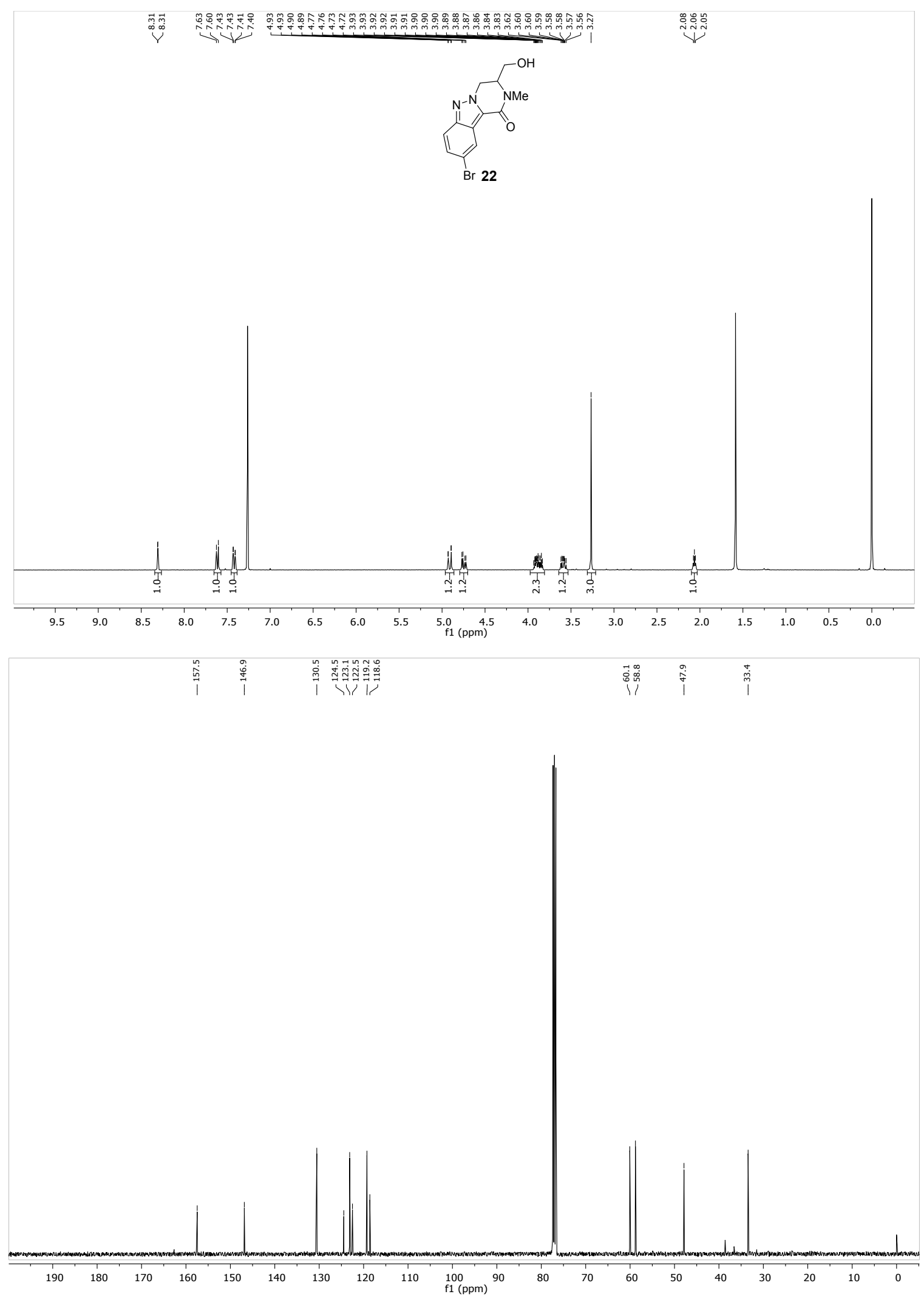


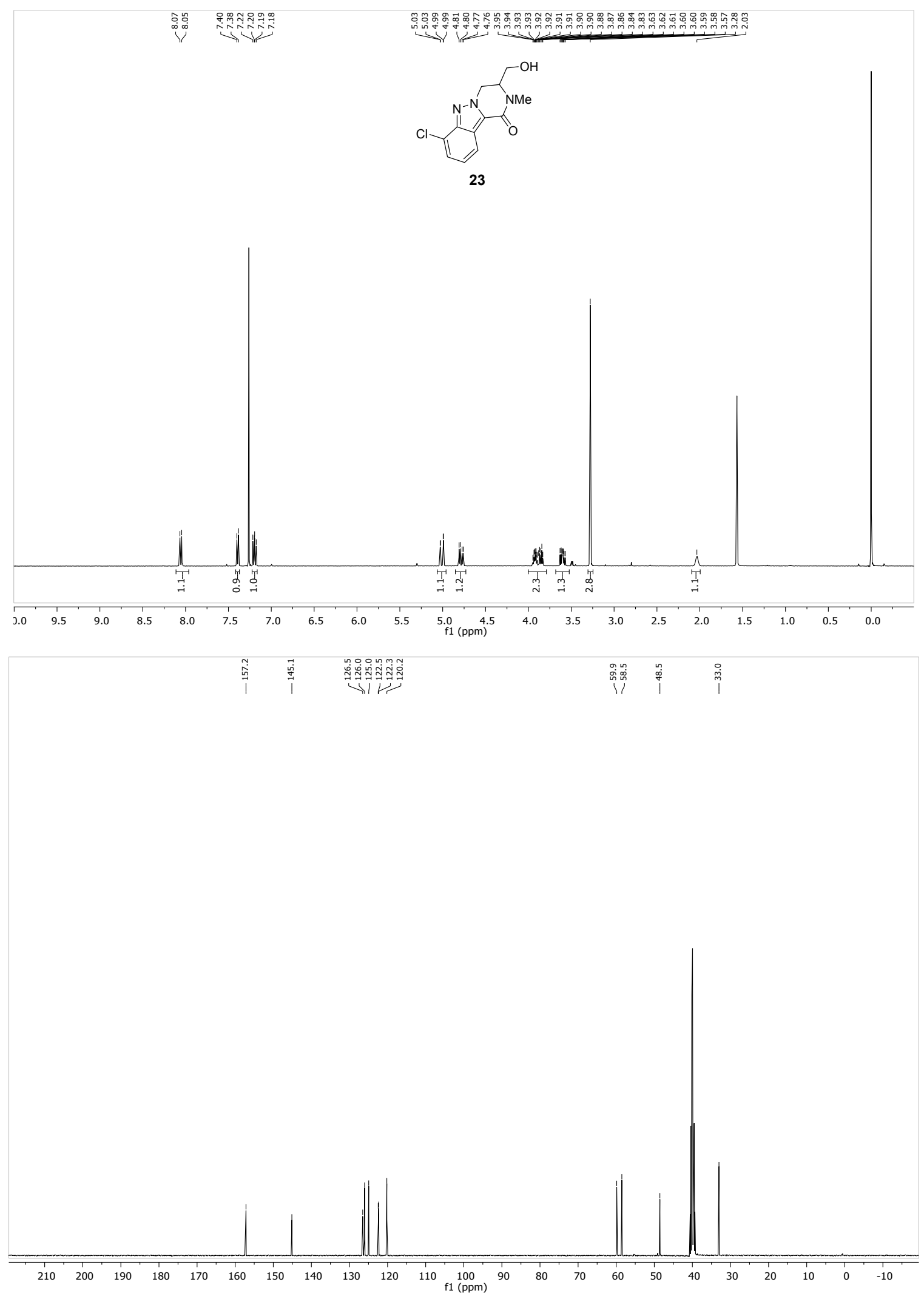




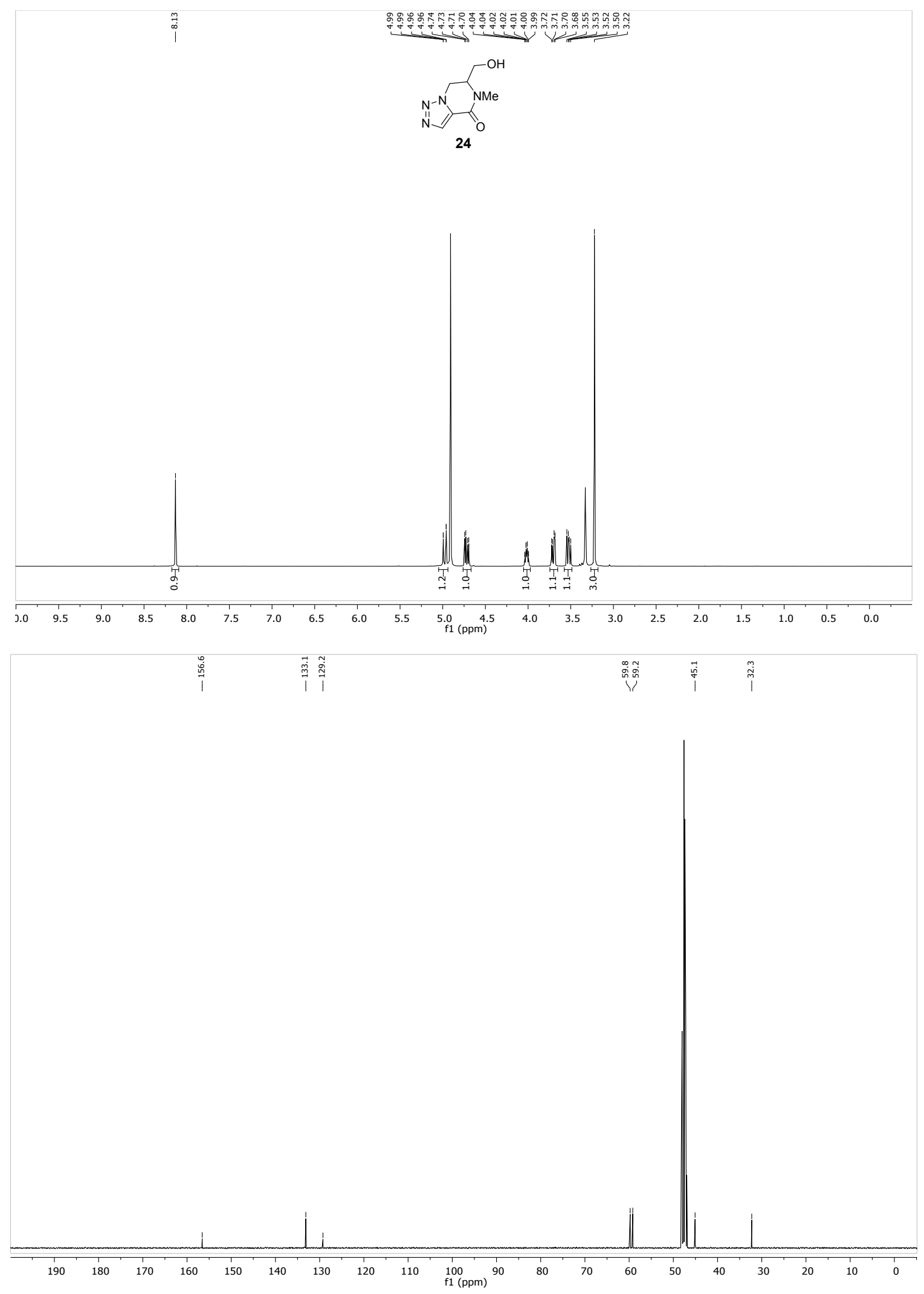




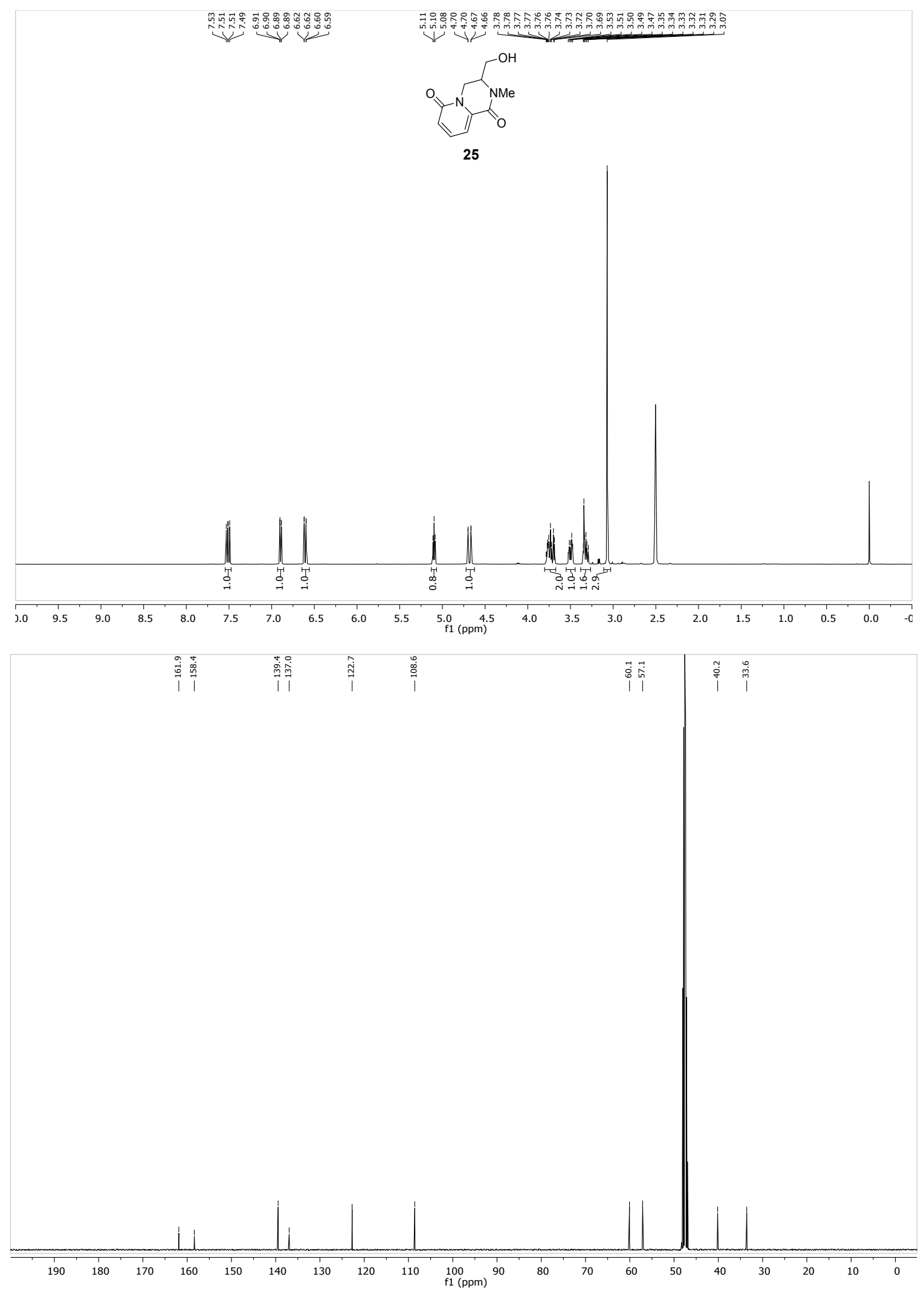



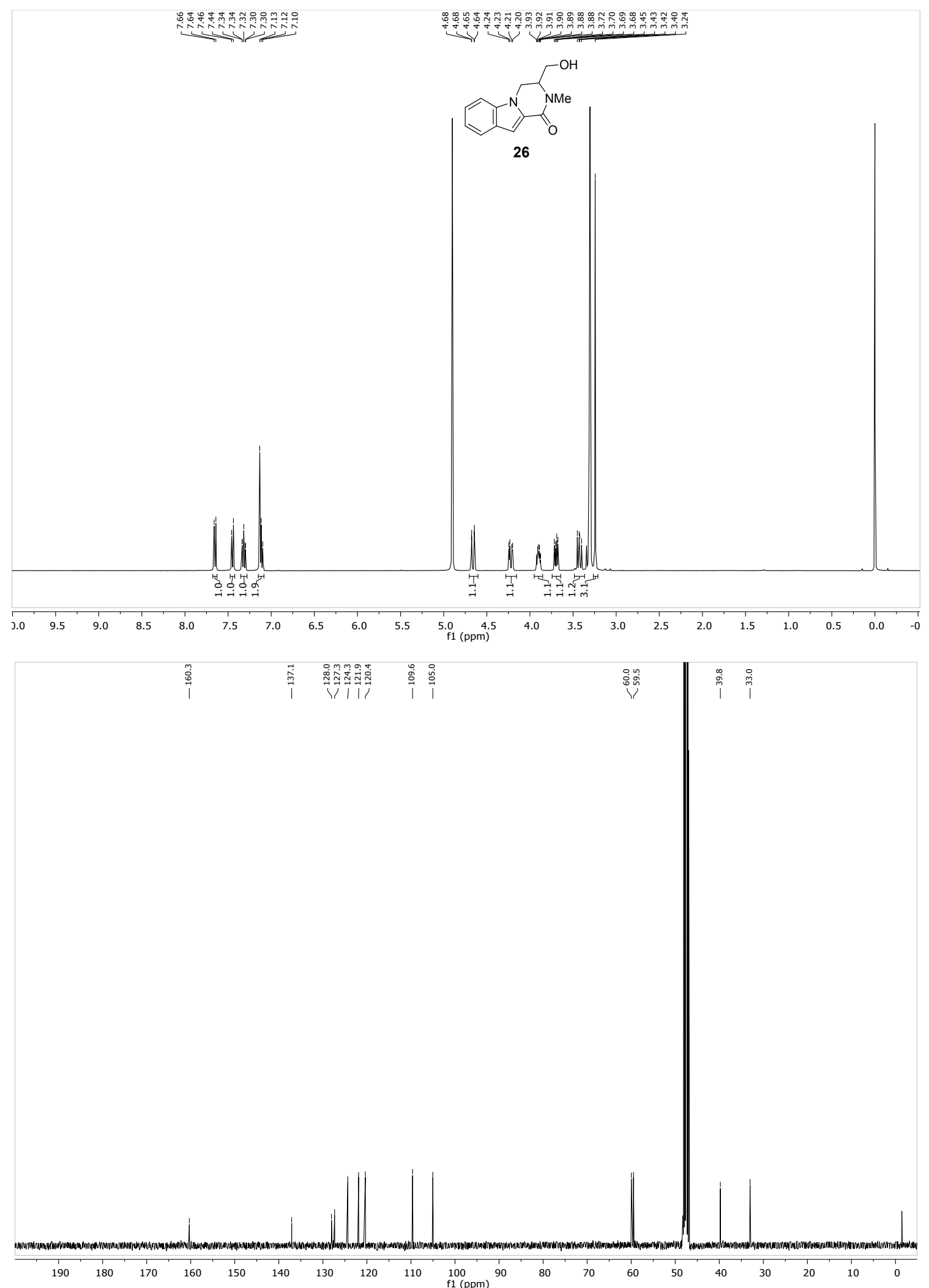


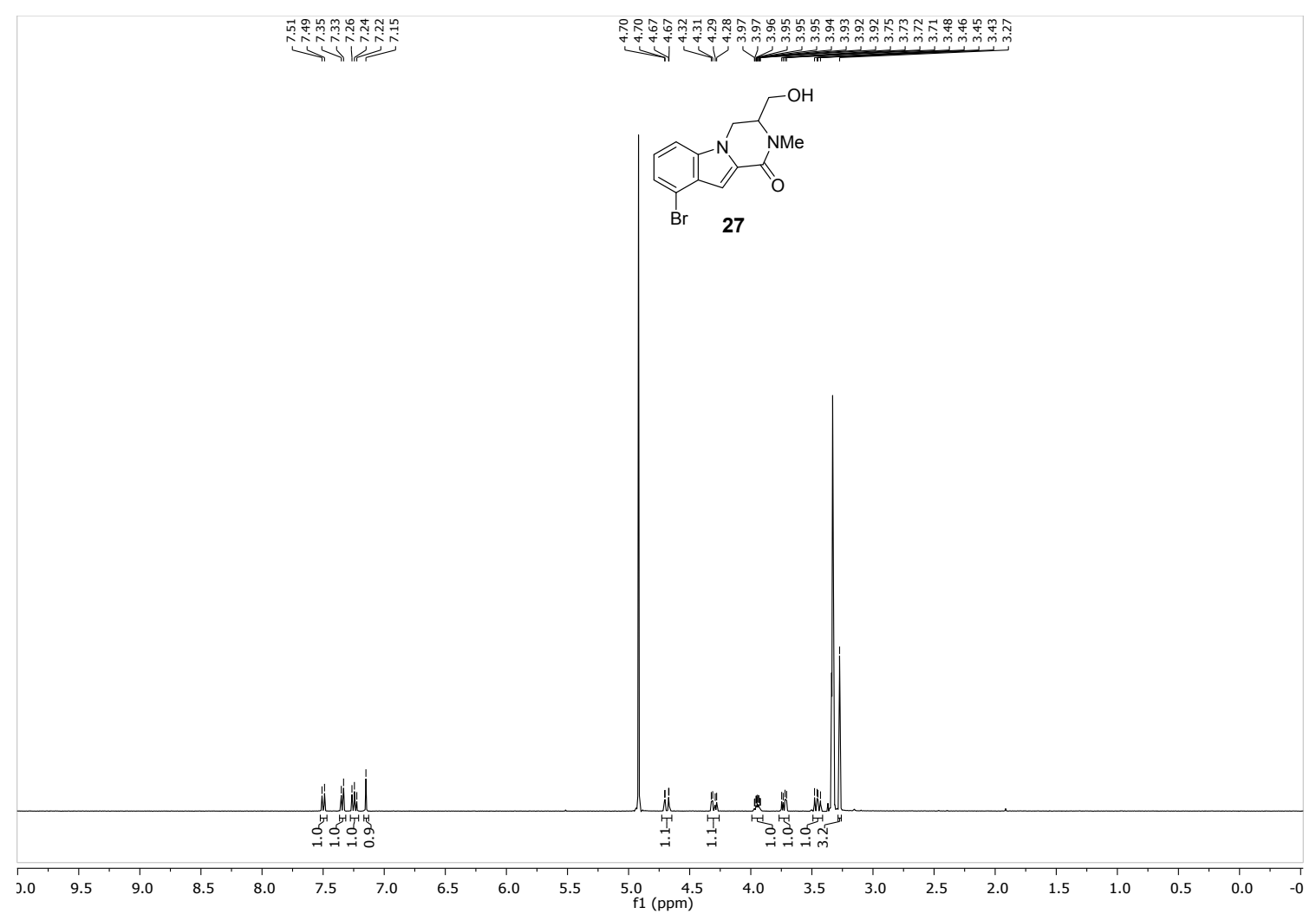

商

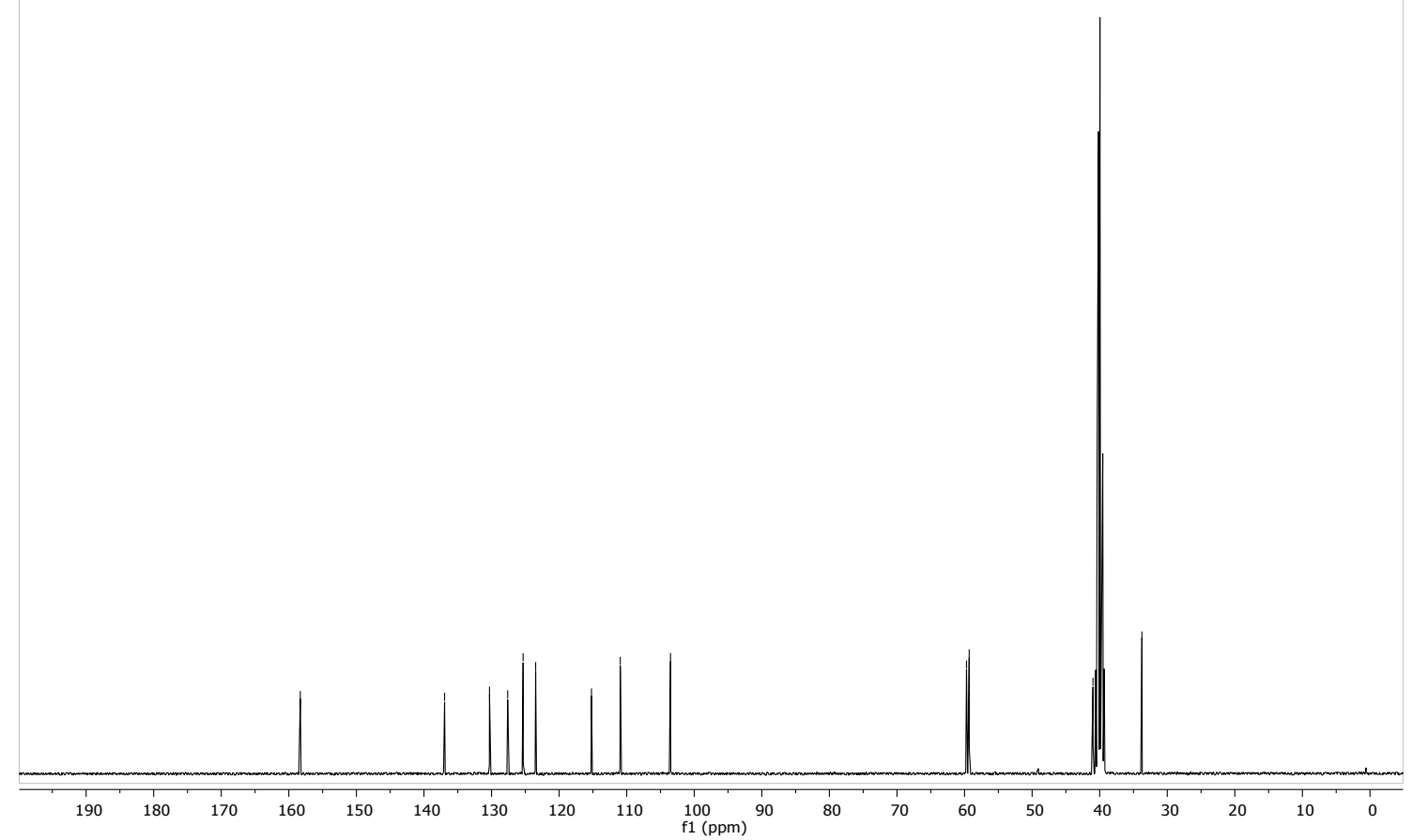



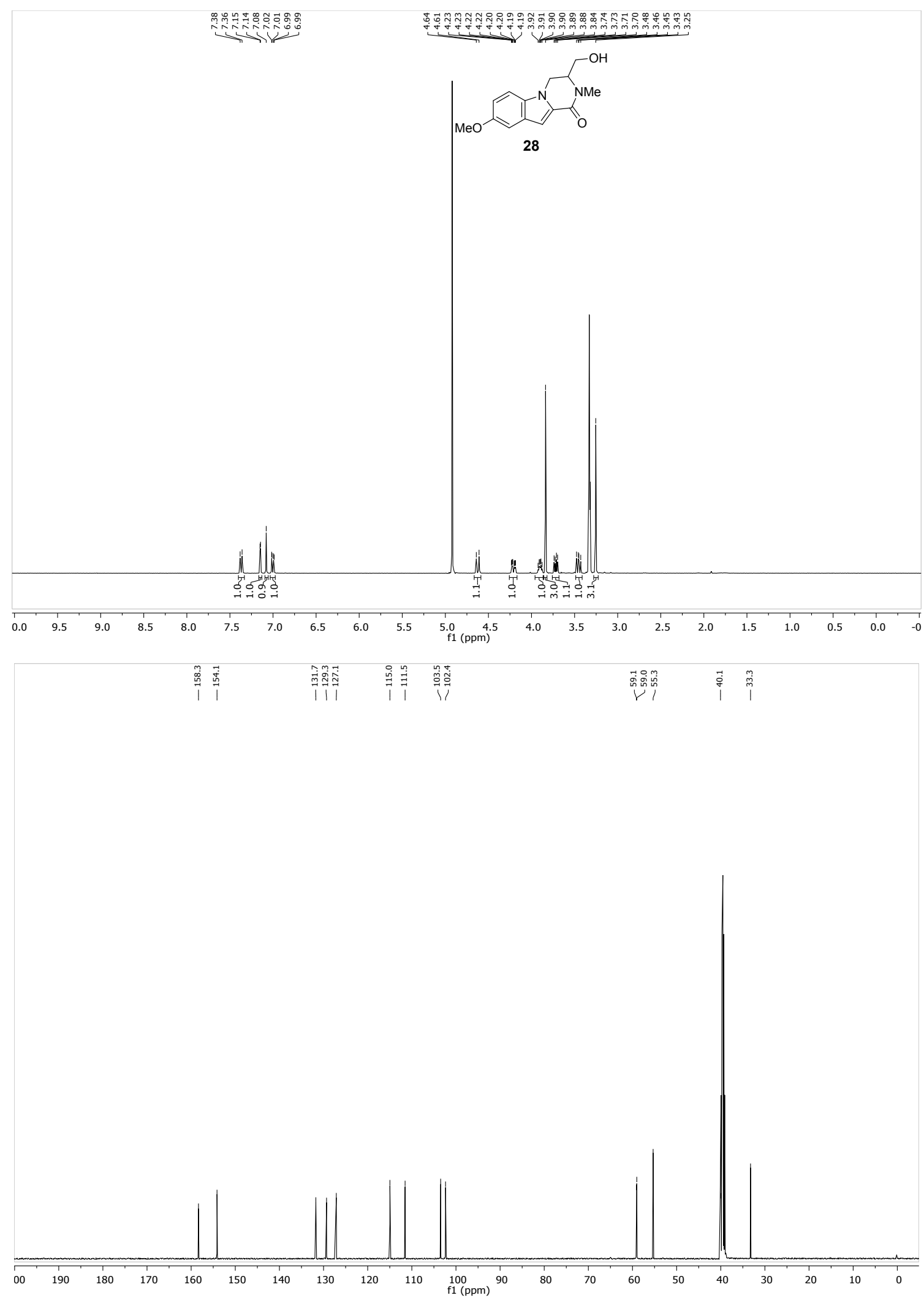

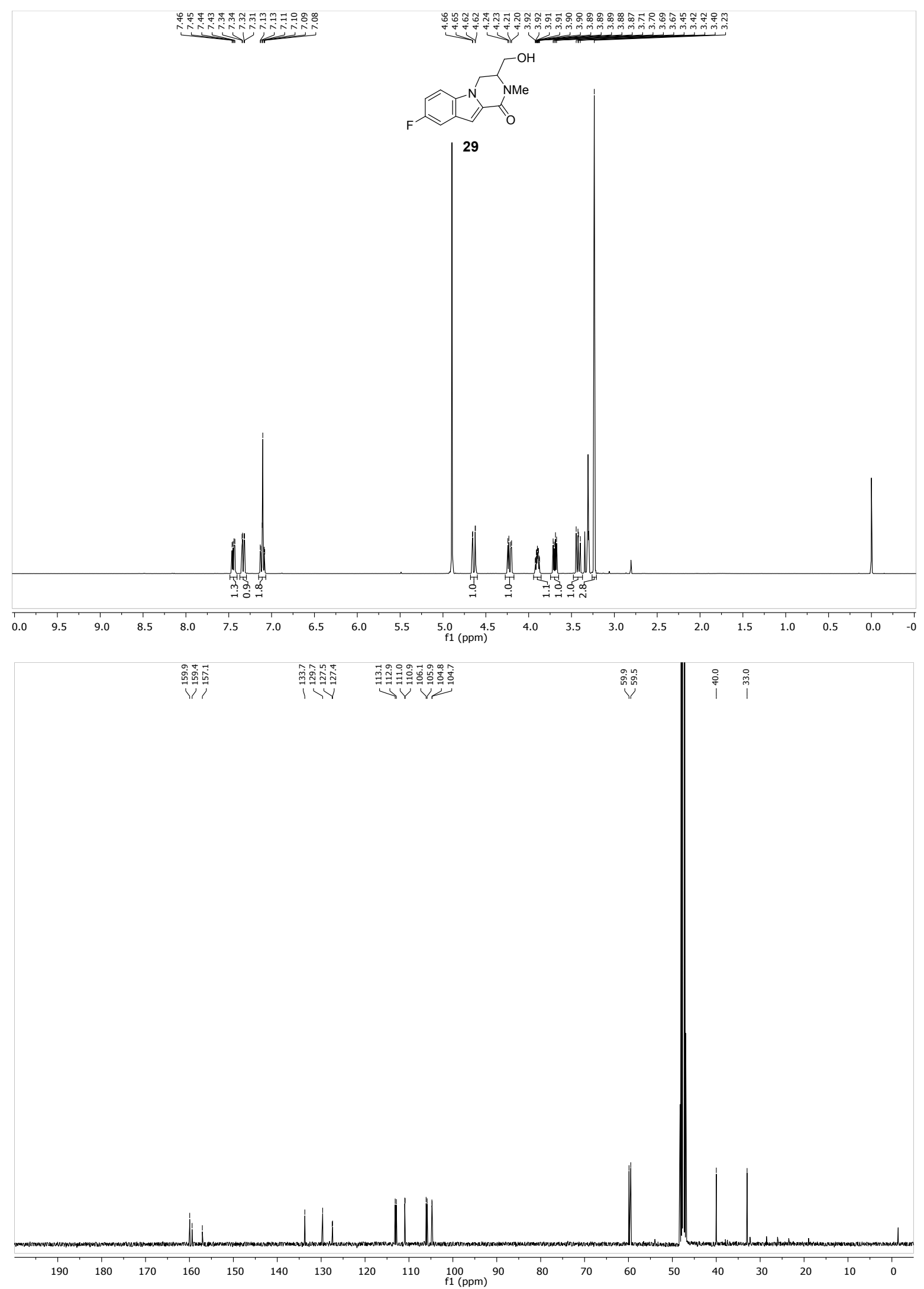


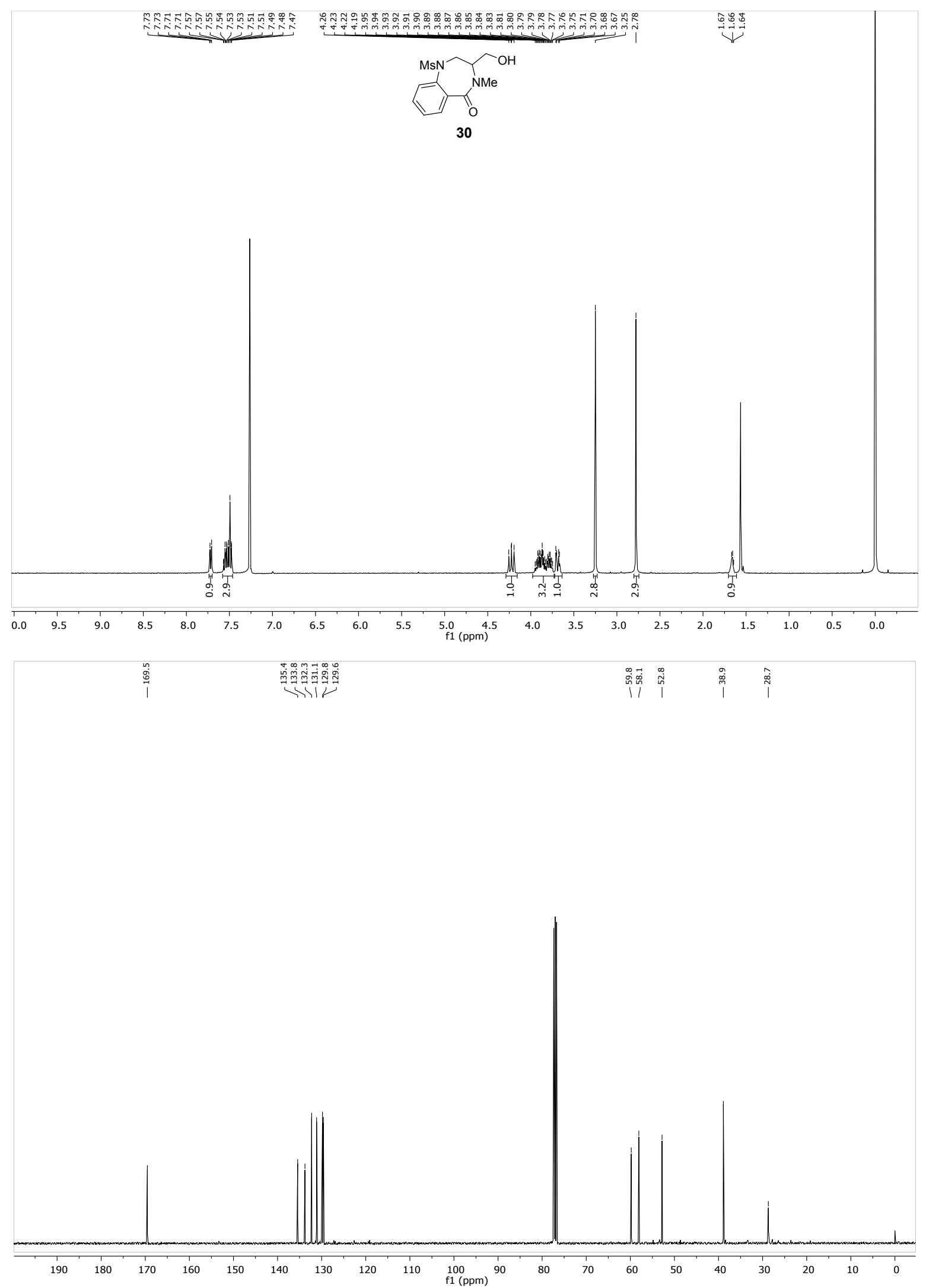



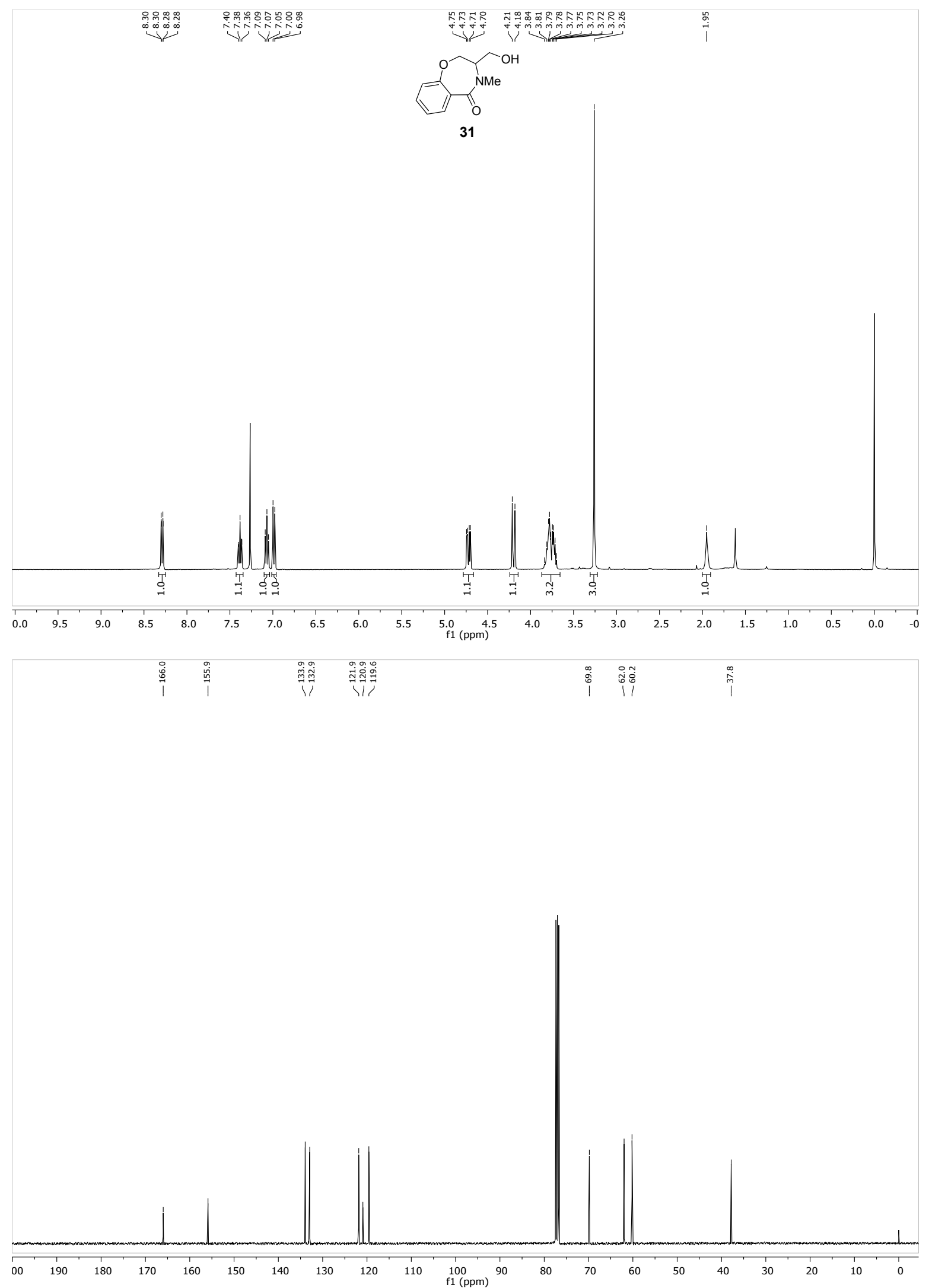

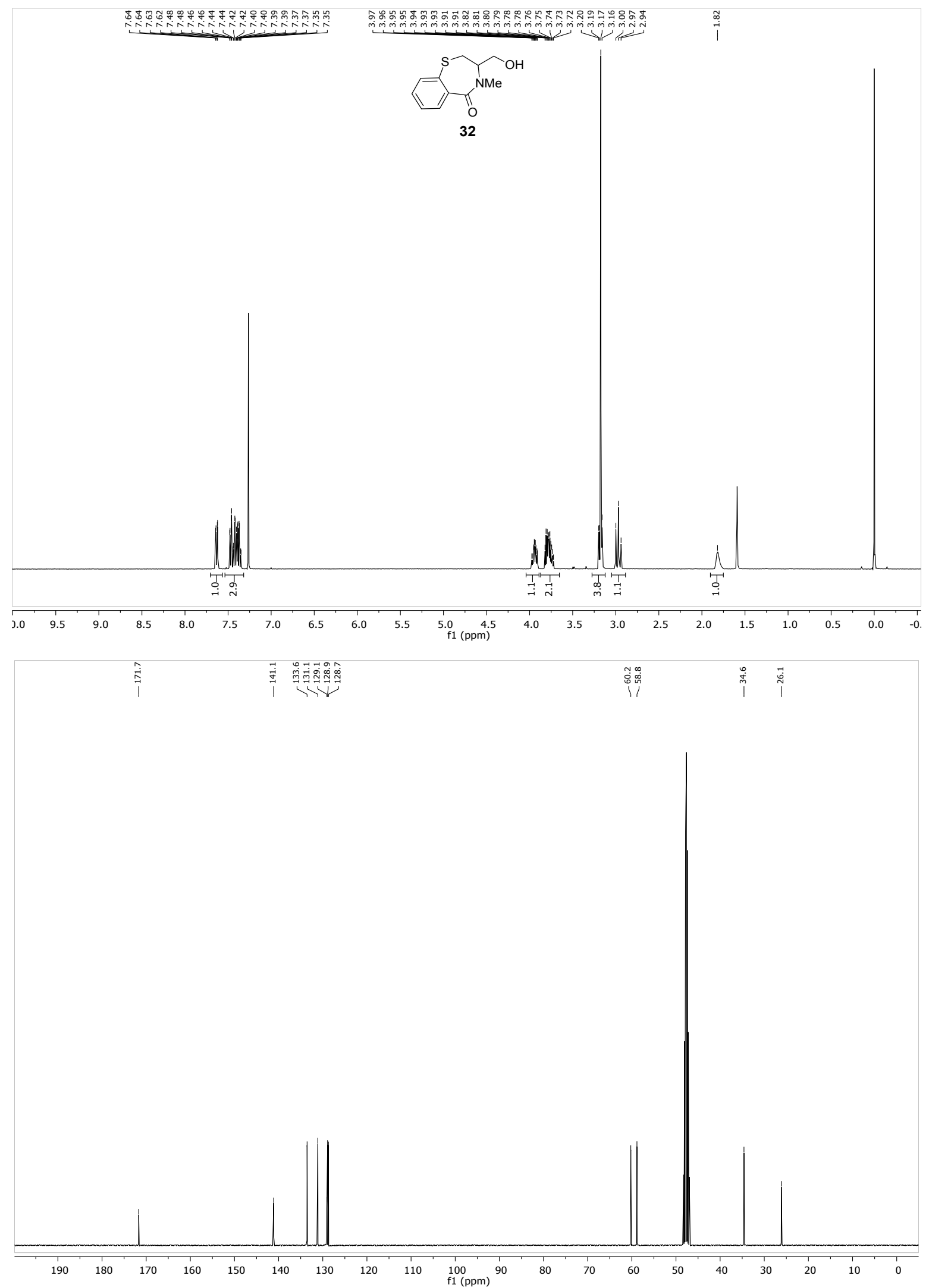

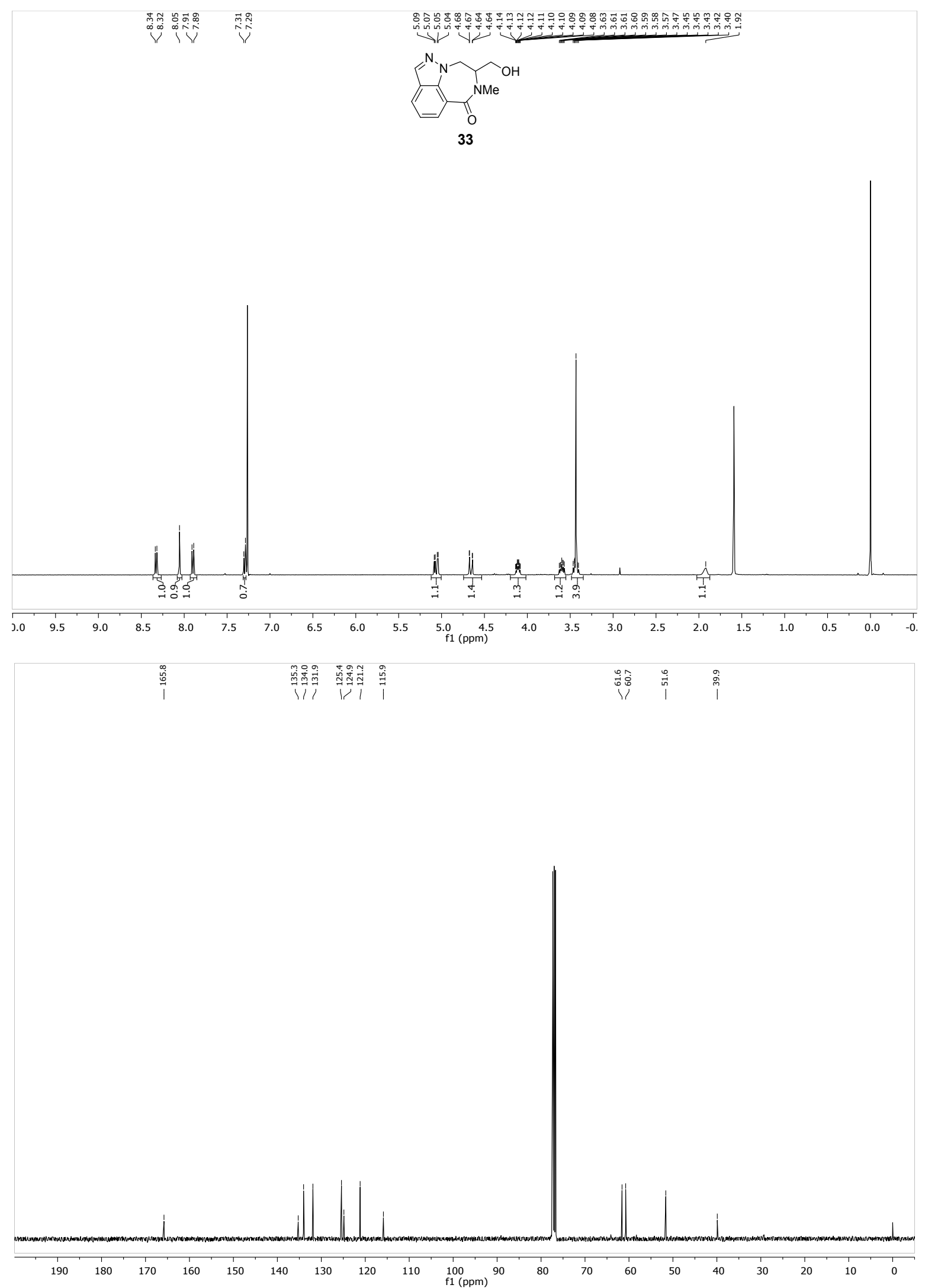

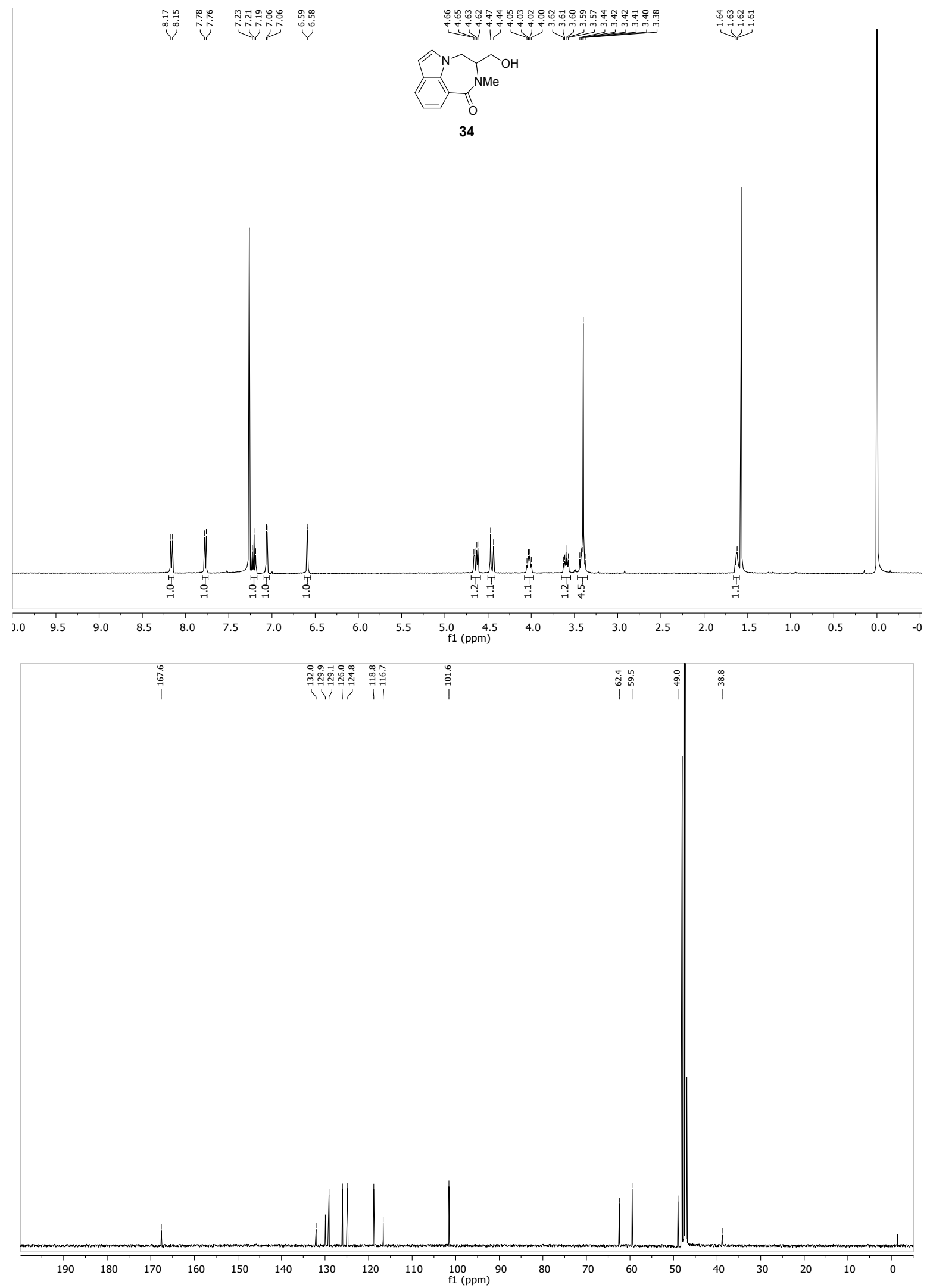

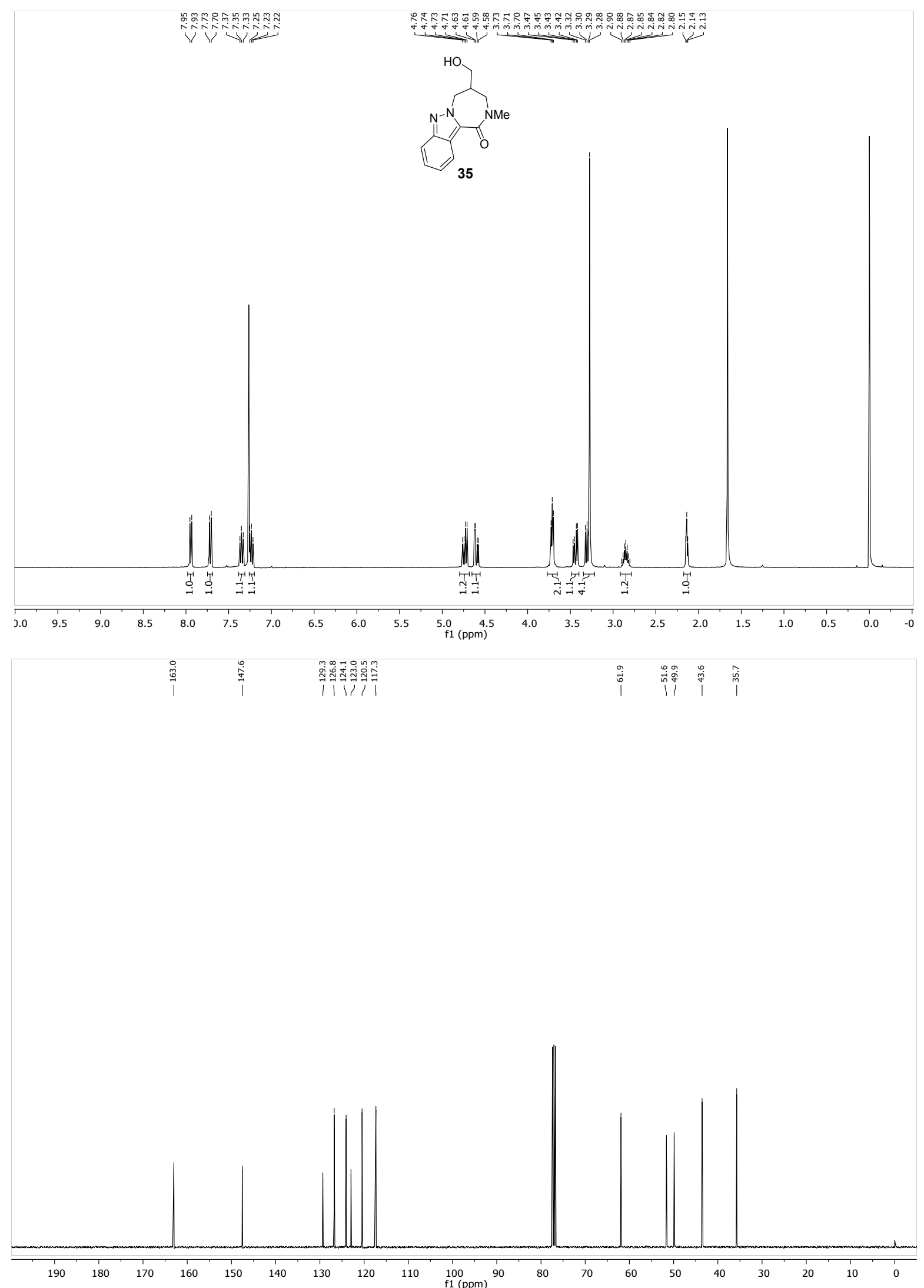

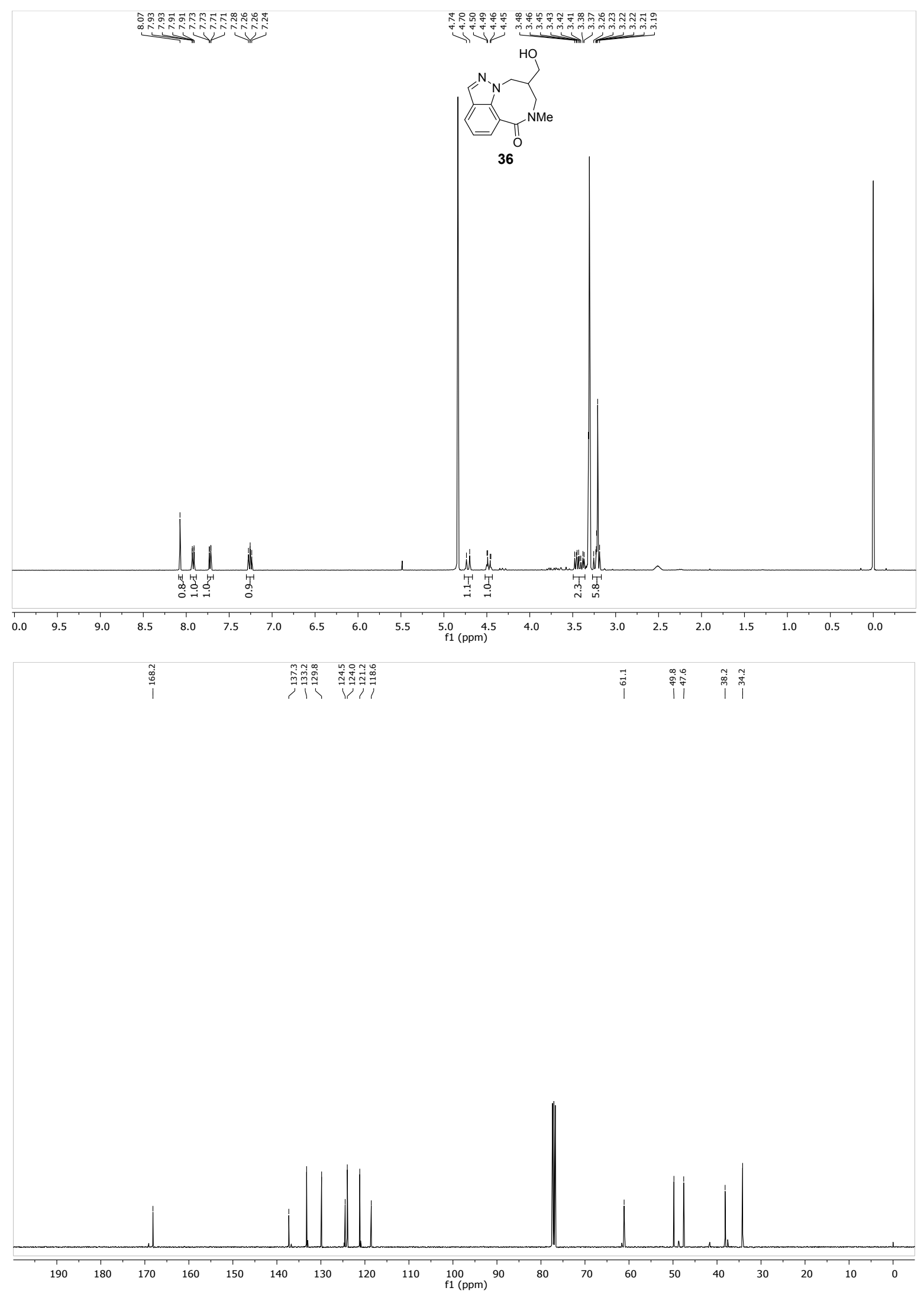


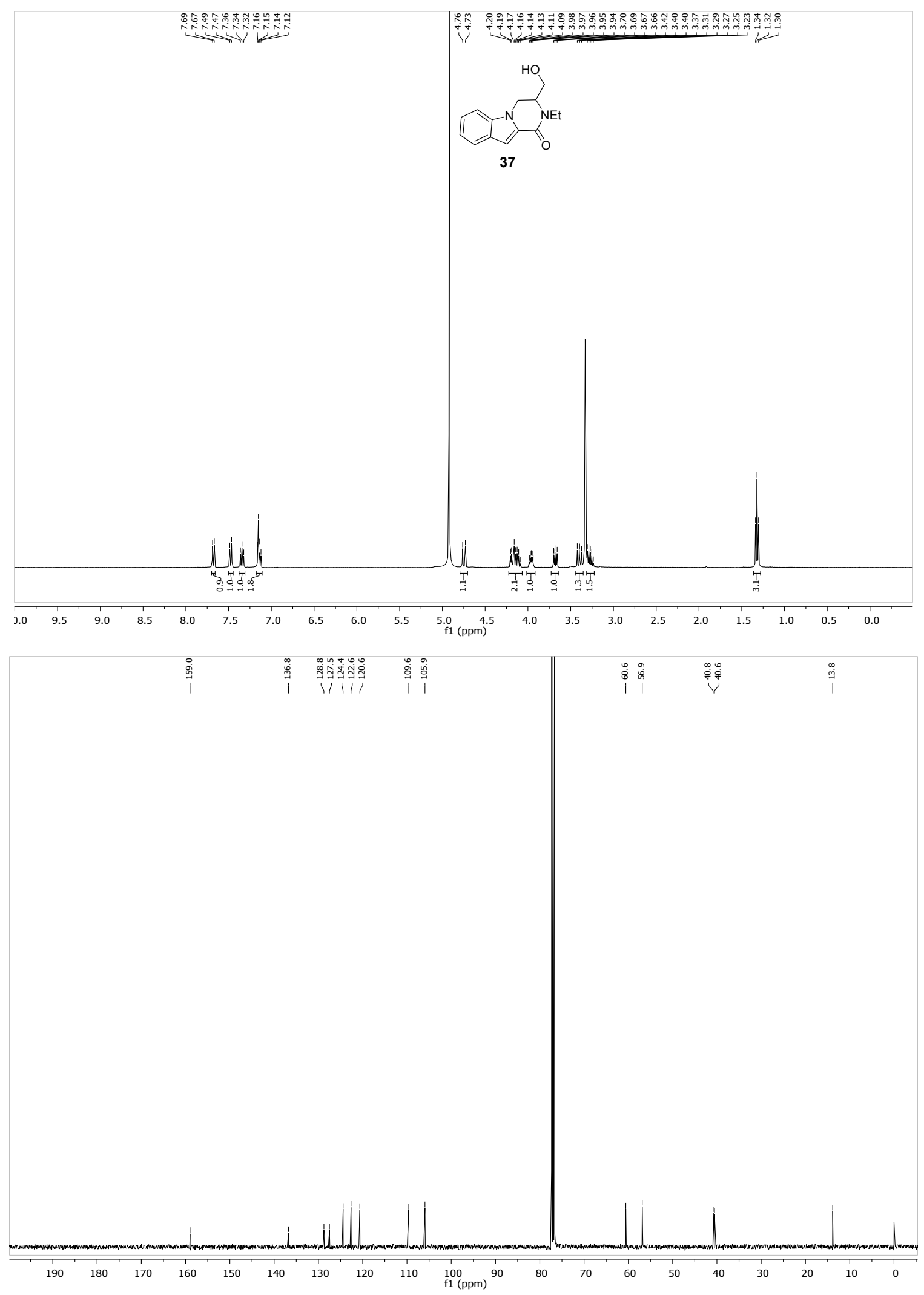



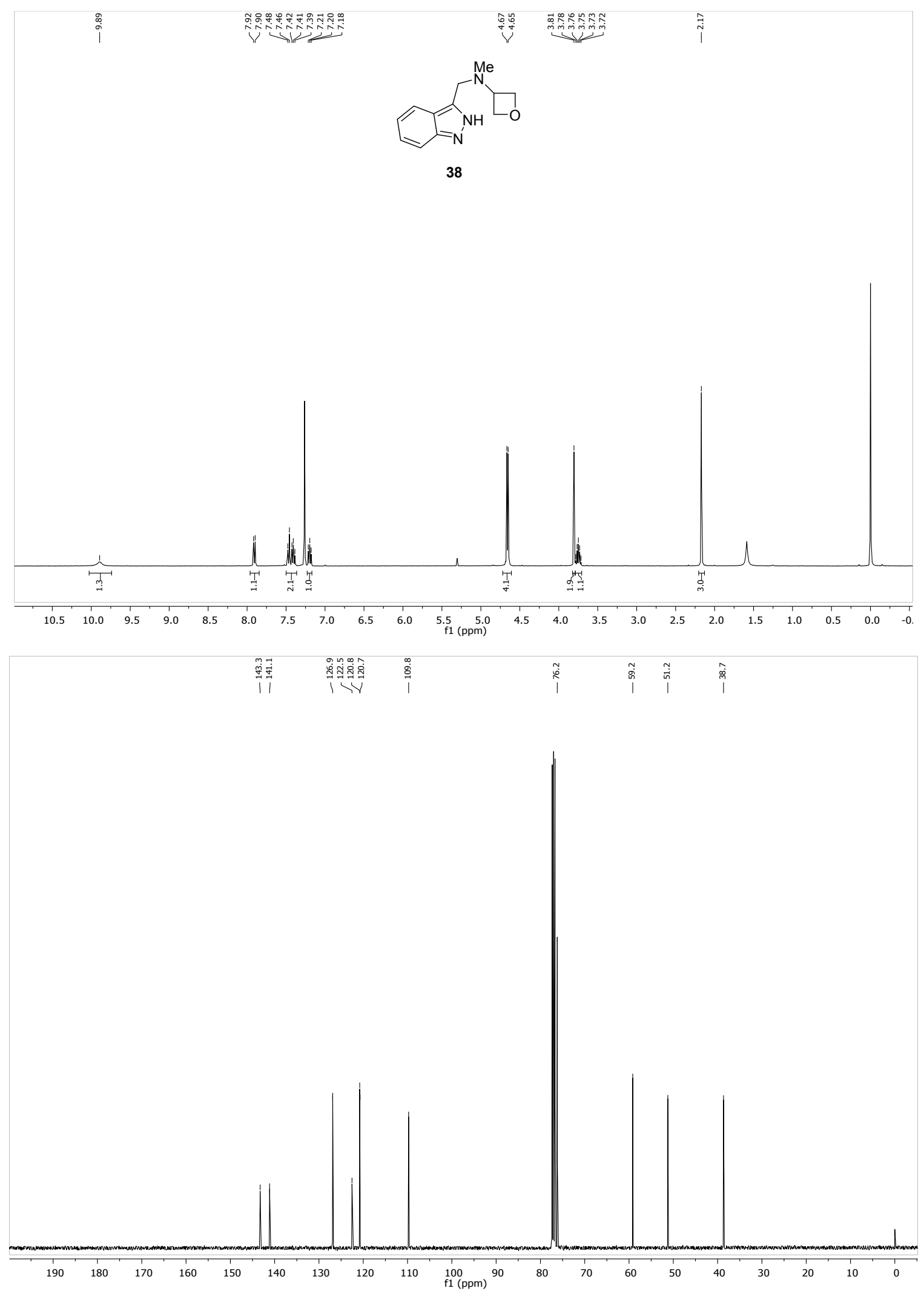


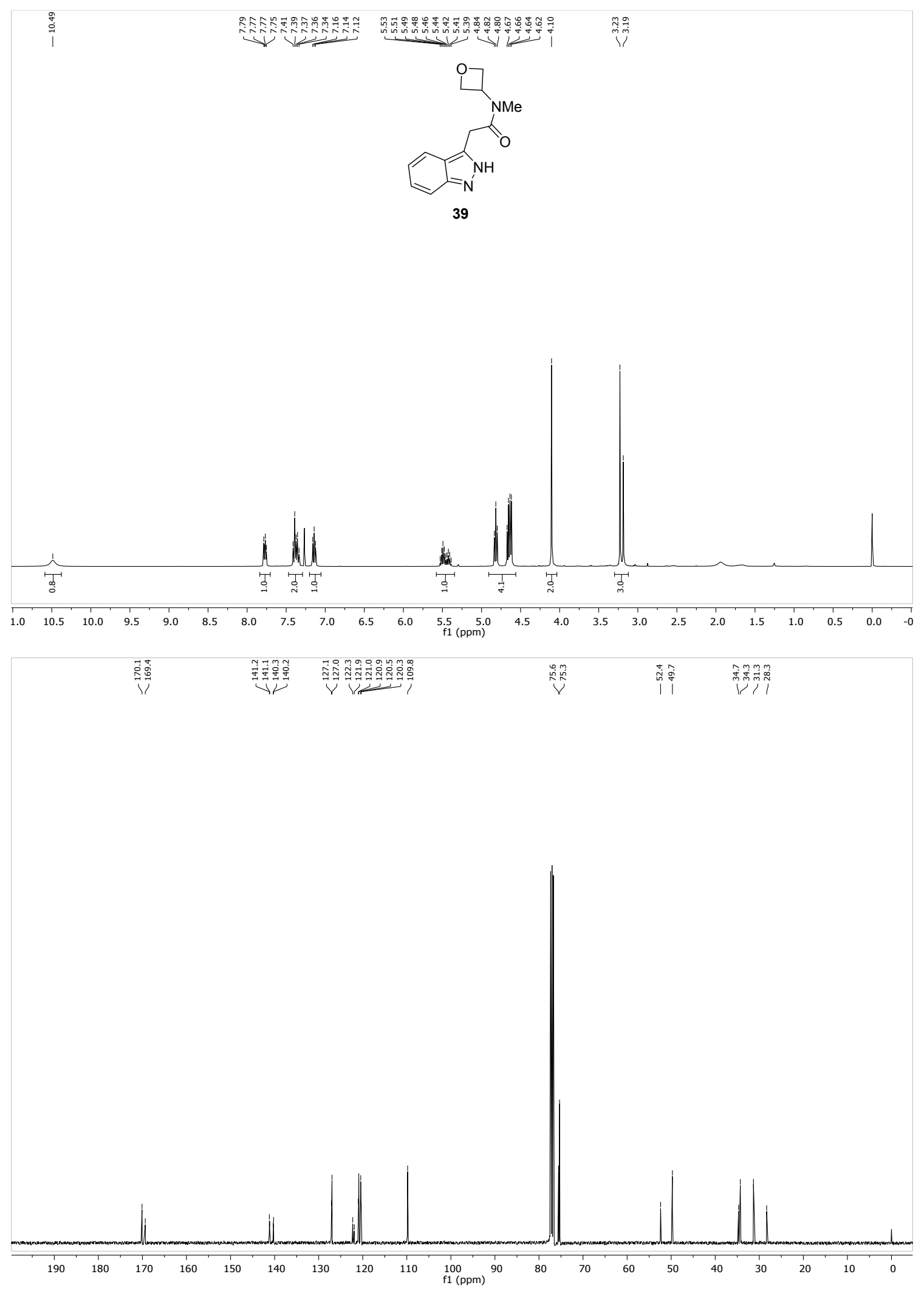




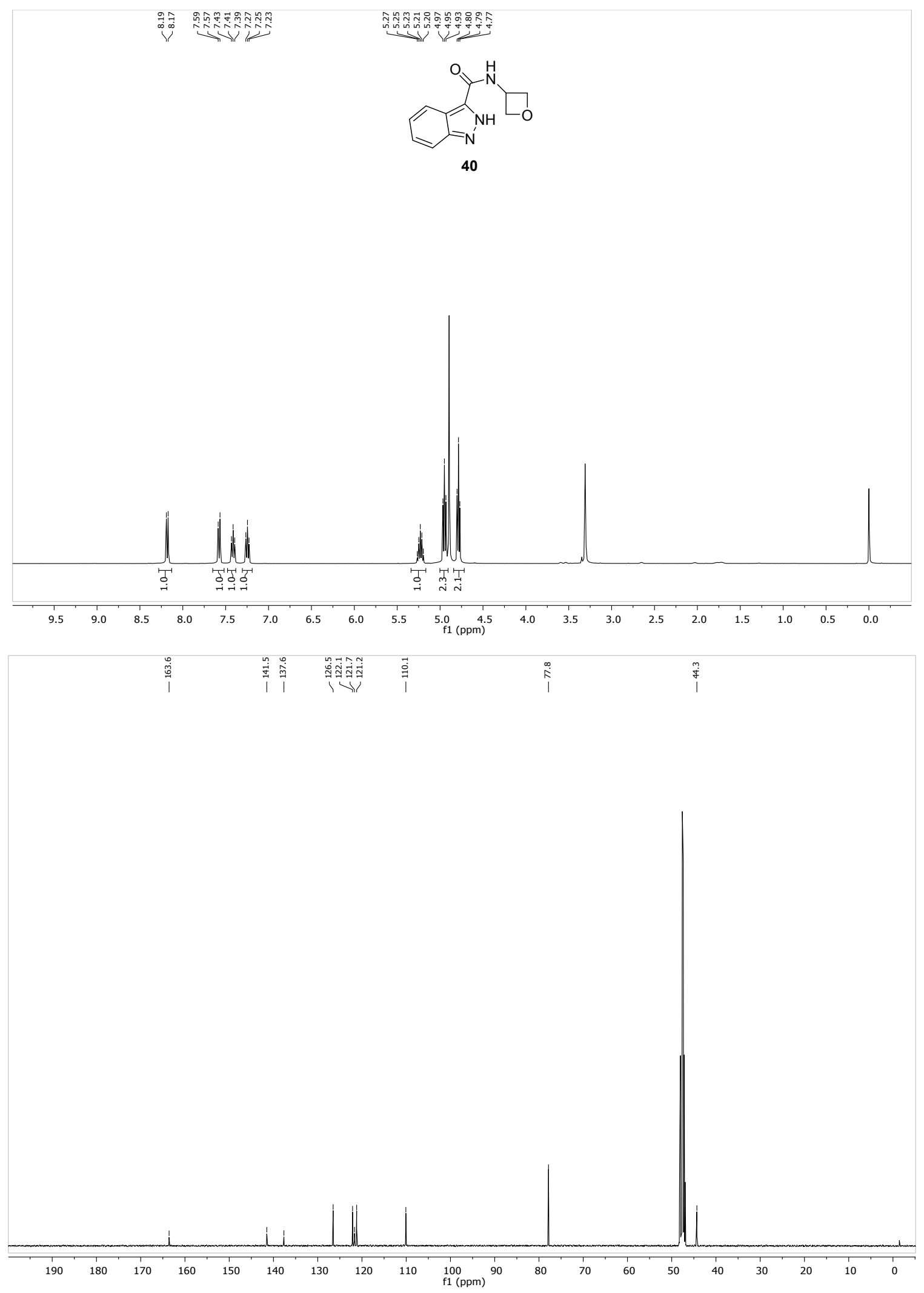




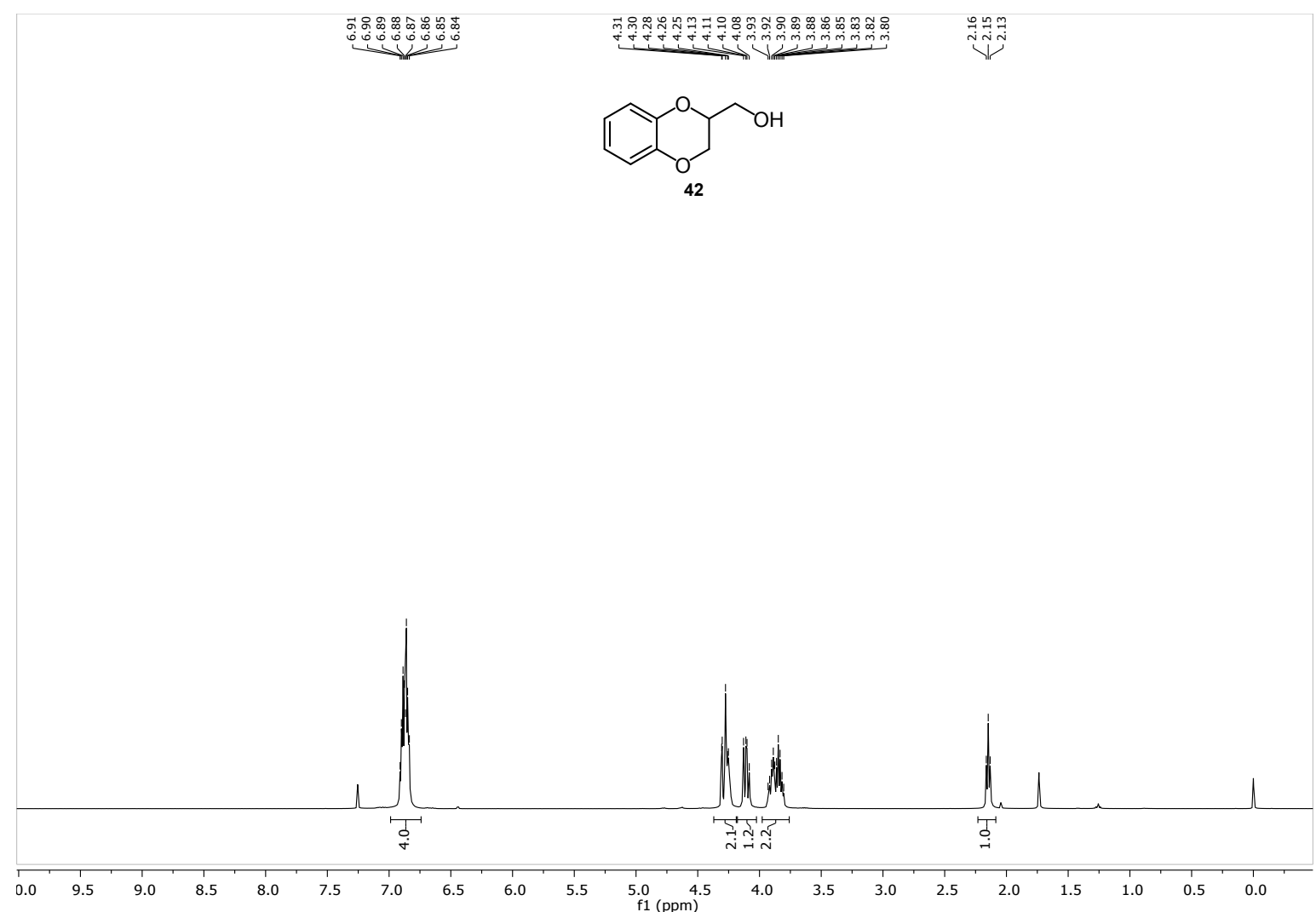

